\title{
Tools and techniques for solvent selection: green solvent selection guides
}

\author{
Fergal P. Byrne, Saimeng Jin, Giulia Paggiola, Tabitha H. M. Petchey, James H. Clark ${ }^{*}$, Thomas J. Farmer, \\ Andrew J. Hunt, C. Robert McElroy and James Sherwood
}

\begin{abstract}
Driven by legislation and evolving attitudes towards environmental issues, establishing green solvents for extractions, separations, formulations and reaction chemistry has become an increasingly important area of research. Several general purpose solvent selection guides have now been published with the aim to reduce use of the most hazardous solvents. This review serves the purpose of explaining the role of these guides, highlighting their similarities and differences. How they can be used most effectively to enhance the greenness of chemical processes, particularly in laboratory organic synthesis and the pharmaceutical industry, is addressed in detail.
\end{abstract}

Keywords: Green solvents, Solvent selection guide, Bio-based solvent, Green chemistry metrics

\section{Background}

Solvents have received much attention under the remit of green chemistry [1-5]. This can be ascribed to the large volume of solvent typically used in a reaction (especially at the purification stage) or in a formulation $[6,7]$. Despite this, the solvent is not directly responsible for the composition of a reaction product, nor is it the active component of a formulation. Therefore the use of toxic, flammable, or environmentally damaging solvents would seem unnecessary because these characteristics have no impact on the function or progress of the system in which the solvent is applied. However these unfortunate consequences of solvent use are often linked to the beneficial attributes of the solvent needed for the application. The volatility of solvents permits recovery and purification of the solvent by distillation, but also creates unwanted air emissions and the risk of worker exposure. Amide solvents have the high polarity required to dissolve a broad range of substrates and accelerate reactions [8], but this functionality often implies reproductive toxicity [9]. At the other end of the polarity scale hydrocarbon solvents provide the ability to dissolve oils in extractions and perform separations $[10,11]$, yet at the same time they are

\footnotetext{
*Correspondence: james.clark@york.ac.uk Green Chemistry Centre of Excellence, Department of Chemistry, University of York, Heslington, York YO10 5DD, UK
}

highly combustible, and their low water solubility (high $\log \mathrm{P}$ ) is linked to bioaccumulation and aquatic toxicity $[12,13]$.

In attempts to eliminate undesirable solvents, replacement strategies often seek structurally related compounds not yet covered by the legislative and regulatory measures usually required to force action in this respect. Thus benzene, since its formal recognition as a carcinogen in the mid-twentieth century, is generally replaced by toluene $[14,15]$. Similarly the Montreal protocol has restricted the use of carbon tetrachloride since 1989 because of its role in depleting the ozone layer $[16,17]$. Typically the halogenated solvents chloroform and dichloromethane (DCM) are now used instead. It is important to emphasise that these measures have proven to be short sighted with respect to increasingly strict chemical controls worldwide. Toluene is in fact suspected of damaging the unborn child and of organ damage through prolonged exposure $[18,19]$. Chloroform and DCM are likely to be carcinogenic to humans according to the World Health Organization IARC evaluations [15]. In addition, DCM, even as a short-lived halogenated substance has now been shown to be ozone depleting as well [20].

The European regulation concerning the 'Registration, Evaluation, Authorisation and Restriction of Chemicals' 
(REACH) has introduced restrictions on toluene, chloroform and DCM with specific conditions (Table 1) [21-23]. REACH is now affecting the import and usage of a wide range of chemicals in Europe. Any products found not to comply with the conditions established in $\mathrm{REACH}$ are removed from the market through the 'rapid alert system for dangerous non-food products' (RAPEX) information scheme [24]. To take just a small sample, in 2015 banned products have included glues containing toluene [25], chloroform [26], or benzene [27], and sometimes in alarmingly significant proportions [28].

Looking ahead to future European bans on solvents, candidate chemicals are placed on a list of 'substances of very high concern' (SVHC) prior to REACH restrictions being imposed [30]. Notably for solvent users the amides $N, N$-dimethylformamide (DMF), $N, N$-dimethylacetamide (DMAc), and $N$-methylpyrrolidinone (NMP), as well as certain hydroxyethers and chlorinated solvents have fallen under scrutiny (Table 2). Solvents that are similar structurally can be easily sourced as drop-in replacements, but are likely to present many of the same environmental, health, and safety (EHS) problems seen in historical examples of solvent substitution. Environmental agencies in other regions have their own approaches to regulating hazardous chemicals, with solvents strongly impacted because of their VOC status and hence high risk of exposure [31].

In an attempt to categorise solvents with respect to their EHS profiles, solvent selection guides have been produced to give more information than the "black and white' conclusions of regulatory assessments. The scope of this review addresses the substitution of conventional organic solvents with greener, ideally bio-based organic solvents with the help of solvent selection tools. The development of more sophisticated approaches to solvent substitution that also incorporate the performance of the solvent, or the design of tailor-made solvents for an application, will also be alluded to but do not form the basis of significant discussion in the present work.

\section{Defining green solvents}

The question posed by Fischer and co-workers at ETH Zurich (otherwise known as the Swiss Federal Institute of Technology) in the title of their 2007 article is a fundamental one; "what is a green solvent" [32]? Their answer is a now influential, two tiered assessment of environmental, health and safety (EHS) and energy demand (which can be regarded as a quick LCA type calculation). By understanding the energy required to produce a solvent, and the options available at end-of-life to recover some of that energy, the net cumulative energy demand (CED) of solvent production can be calculated. Energy reclamation can be achieved by incineration, or by offsetting resource demand by recycling the solvent. Purification of used solvent by distillation is less energy intensive than the production of an equivalent volume of new solvent. Incineration directly produces energy but requires more solvent to be produced in its place.

The approach that offers the greater reduction of CED depends on the type of solvent (Fig. 1). In Fig. 1 the energy required for the production of $1 \mathrm{~kg}$ of solvent is shown as bars with blue, solid shading. The energy to distil a solvent rather than produce more is shown as the red striped bars. The saved energy (distillation credit) is shown underneath. The incineration credit is the energy recovery from incineration, leaving a reduced CED as

Table 1 REACH restrictions on the solvents toluene, DCM and chloroform with hazard codes also provided [21-23]

\begin{tabular}{|c|c|c|}
\hline Solvent & Condition $^{a}$ & Hazards ${ }^{\mathbf{b}}$ \\
\hline & $\begin{array}{l}\text { "Shall not be placed on the market, or used, as a substance or in } \\
\text { mixtures in a concentration equal to or greater than } 0.1 \% \text { by weight } \\
\text { where the substance or mixture is used in adhesives or spray paints } \\
\text { intended for supply to the general public" }\end{array}$ & $\begin{array}{l}\text { May be fatal if swallowed and enters airways }(\mathrm{H} 304) \\
\text { Suspected of damaging the unborn child }(\mathrm{H} 361 \mathrm{~d}) \\
\text { May cause damage to organs through prolonged or repeated } \\
\text { exposure }(\mathrm{H} 373)\end{array}$ \\
\hline $\mathrm{H}-\stackrel{\mathrm{I}}{\mathrm{C}}-\mathrm{Cl}$ & $\begin{array}{l}\text { "Paint strippers containing dichloromethane in a concentration } \\
\text { equal to or greater than } 0.1 \% \text { by weight shall not be placed on the } \\
\text { market" }\end{array}$ & Suspected of causing cancer $(\mathrm{H} 351)$ \\
\hline \multicolumn{3}{|l|}{$\mathrm{DCM}$} \\
\hline $\begin{array}{l}\mathrm{Cl} \\
\mathrm{Cl} \\
\text { Chloroform } \\
\mathrm{H}\end{array}$ & $\begin{array}{l}\text { "Shall not be placed on the market, or used, as substances, as con- } \\
\text { stituents of other substances, or in mixtures in concentrations equal } \\
\text { to or greater than } 0.1 \% \text { by weight, where the substance or mixture } \\
\text { is intended for supply to the general public and/or is intended for } \\
\text { diffusive applications such as in surface cleaning and cleaning of } \\
\text { fabric" }\end{array}$ & Suspected of causing cancer (H351) \\
\hline
\end{tabular}

\footnotetext{
a Conditions are abbreviated and/or paraphrased from the full text found in Regulation (EC) No 1907/2006 (REACH) [21-23]

b Hazard codes defined according to Regulation (EC) No 1272/2008 (CLP) [29]
} 
Table 2 A non-exhaustive list of solvents featured on the REACH candidate list of SVHC [30]

2-Methoxyethanol and 2-ethoxyethanol and 2-ethoxyethyl acetate

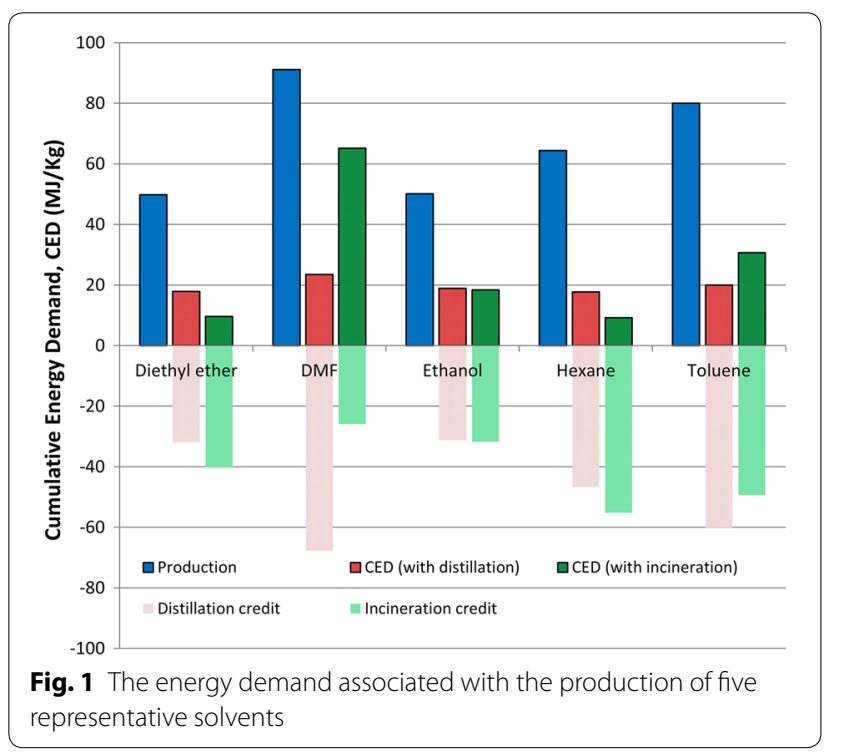

shown with green dotted bars. Most (but not all) hydrocarbons are best incinerated according to this simplified LCA approach (e.g., $n$-hexane but not toluene). The same applies to diethyl ether. The functionalised solvents with longer production routes are best recycled to retain the energy and value invested into the molecule during its original synthesis (e.g., DMF). For ethanol the benefits are quite closely balanced. An even more detailed assessment of energy demand in solvent production has been published by the same authors [33].
The EHS tool that partners the CED assessment has been provided free as an easy to use spreadsheet (.xls) file [34]. The methodology is fully disclosed (Fig. 2), and so providing the necessary data is available, it can be applied to any solvent and any combinations of solvent used in a process. The ranking is derived from hazard and risk codes as well as legislated exposure limits. Therefore a comprehensive safety datasheet should be enough to assess the greenness of a solvent using this approach. Indeed, this was attempted for volatile methyl siloxane solvents in a separate work [35]. However, since 2008 and the introduction of the Global Harmonized System (GHS) as applied by the European Classification, Labelling and Packaging (CLP) regulation [29], this method is in need of revision.

Three criteria in the three EHS categories are combined to complete a numerical ranking system. Lower scores are indicative of greener solvents (Fig. 3). Generally the results are as expected from intuition, with alcohols and esters perceived as greener than hydrocarbons, which in turn have better scores than formaldehyde (5.6) and 1,4-dioxane (5.0). The equal weighting of environmental, health and safety issues could be debated, for the reprotoxic DMF (3.7) registers as greener than peroxide forming ether solvents such as diethyl ether (3.9).

Combining energy demand with the EHS scores of solvents provides a bigger picture of solvent impact. Methyl acetate and alcohol solvents provide the optimum 


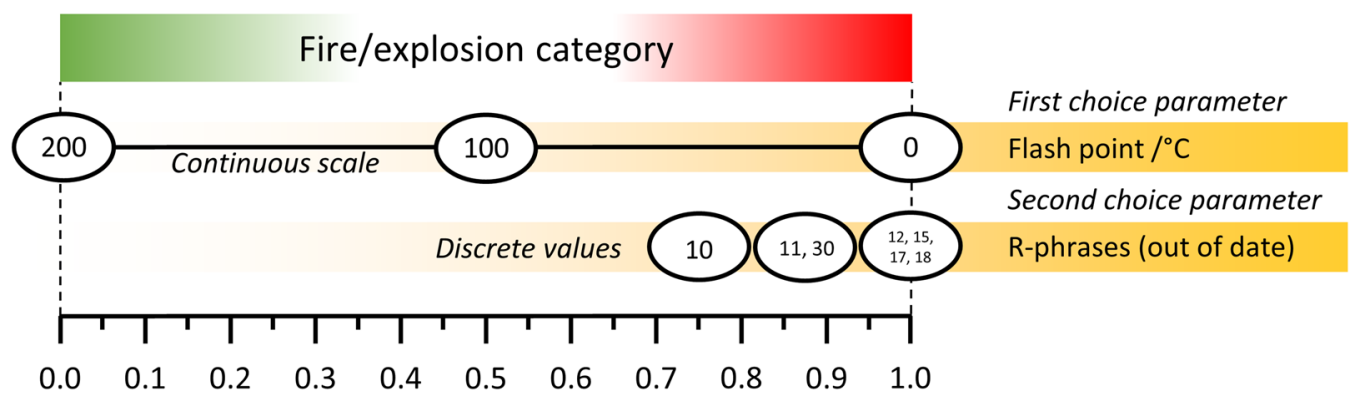

Fig. 2 An example of an ETH Zurich solvent ranking scale (fire/explosion category)

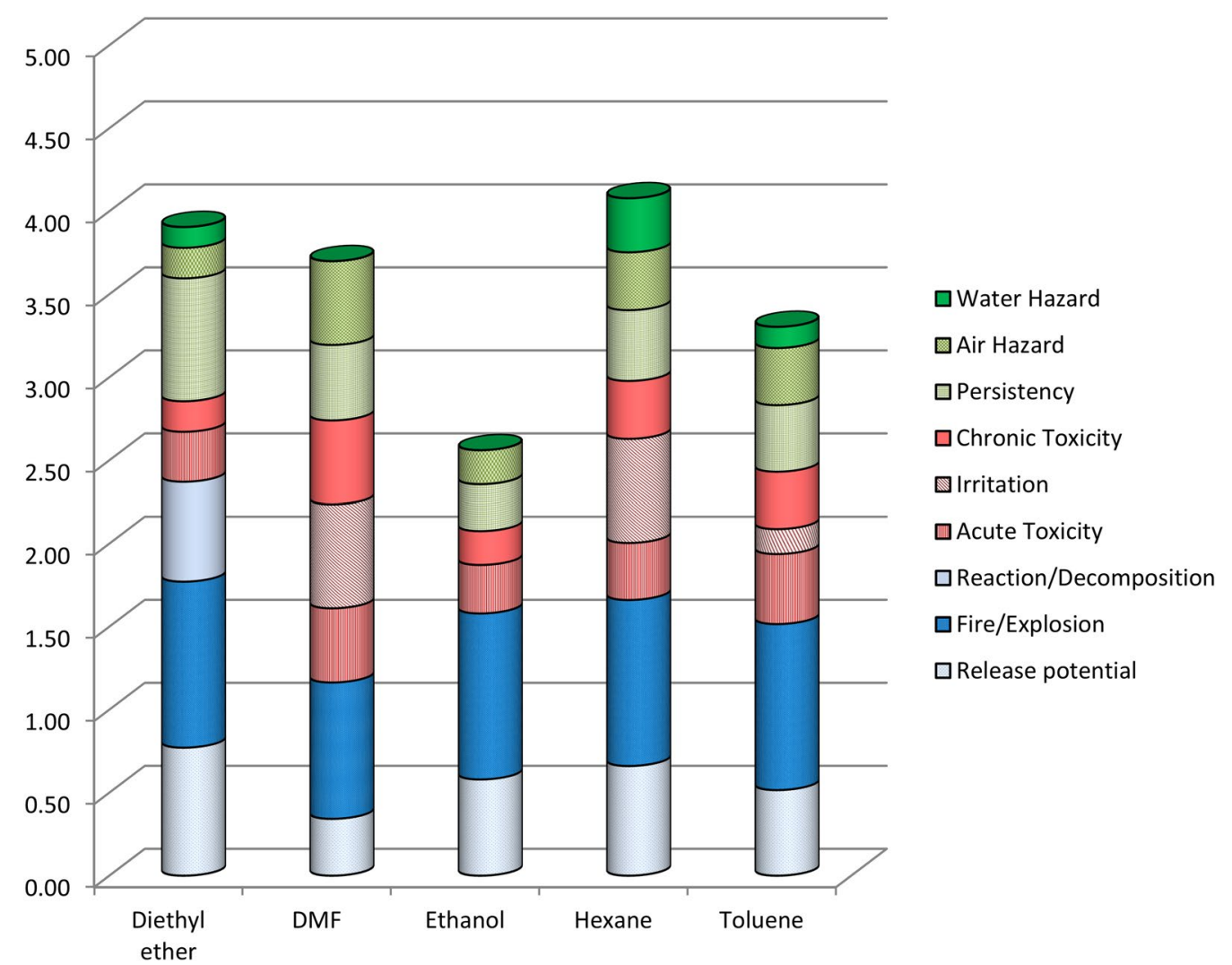

Fig. 3 Environmental health and safety rankings for five representative solvents

balance of low energy demand and a benign EHS profile (Fig. 4). Other useful pieces of information that emerge include the very large energy demand of tetrahydrofuran (THF) production. At $270 \mathrm{MJ} / \mathrm{kg}$, although subsequently revised down nearer to $170 \mathrm{MJ} / \mathrm{kg}$ in a following publication [33], distillation of THF is recommended to reduce the overall CED to just $40.1 \mathrm{MJ} / \mathrm{kg}$. Conversely, diethyl ether (with its lower CED) is best incinerated to minimise the net energy use. The implications of incineration relating to atmospheric emissions is beyond the scope of this assessment but should be considered in practice, especially for nitrogen and sulphur containing solvents that lead to $\mathrm{NO}_{\mathrm{x}}$ and $\mathrm{SO}_{\mathrm{x}}$ emissions upon incineration $[36,37]$.

Along a similar line, Slater and Savelski of Rowan University have also developed a means to generate a comparison between the different solvent options available for a process [38]. They too have produced a spreadsheet that can be used freely by anyone [39]. For each solvent an index composed of 12 environmental parameters was 


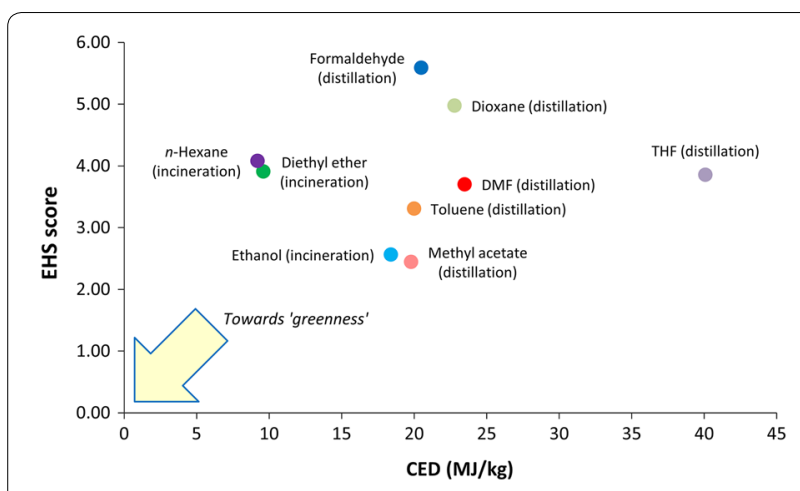

Fig. 4 Map of EHS and CED values for representative solvents

developed, including occupational health considerations (acute toxicity, biodegradation, global warming potential, etc.). Safety considerations such as flash point and peroxide formation are not used as solvent selection parameters. This decision could be perceived as an oversight, at the very least it is a deviation from the EHS approach of ETH Zurich. A summation of the parameters (scaled appropriately with a user defined weighting) produces a score between 0 (most green) and 10 (least green). By factoring in the amount of solvent used, processes can be compared to evaluate the lowest solvent impact. This approach from Rowan University was used to assess routes to sildenafil citrate (the active ingredient in Via$\operatorname{gra}^{\mathrm{TM}}$ ), showing how their 'total process greenness index' decreased by a factor of 400 from the original medicinal chemistry process to the latest commercial route.

From this methodology a solvent selection table containing over 60 solvents was also created [39]. The only chronic toxicity consideration is carcinogenicity, and so reprotoxic solvents such as NMP have a higher perceived greenness (i.e., 3.0 out of 10.0) than what might be expected (for instance 1-butanol scores 4.6). As illustrated by the specific example of hydrocarbon solvents, the Rowan University approach offers better differentiation between solvents compared to the ETH Zurich tool (Fig. 5). In Fig. 5, the scales of the ETH Zurich (left, 0-9) and Rowan University (right, 0-10) solvent greenness assessments have been represented in such a way that the scores for ethanol are equal in magnitude, rather than equate the two dependent variables. Ethanol is included as a benchmark entry because both systems agree that it is a green solvent (ethanol is not being suggested as an alternative to any hydrocarbon solvent). Whereas the

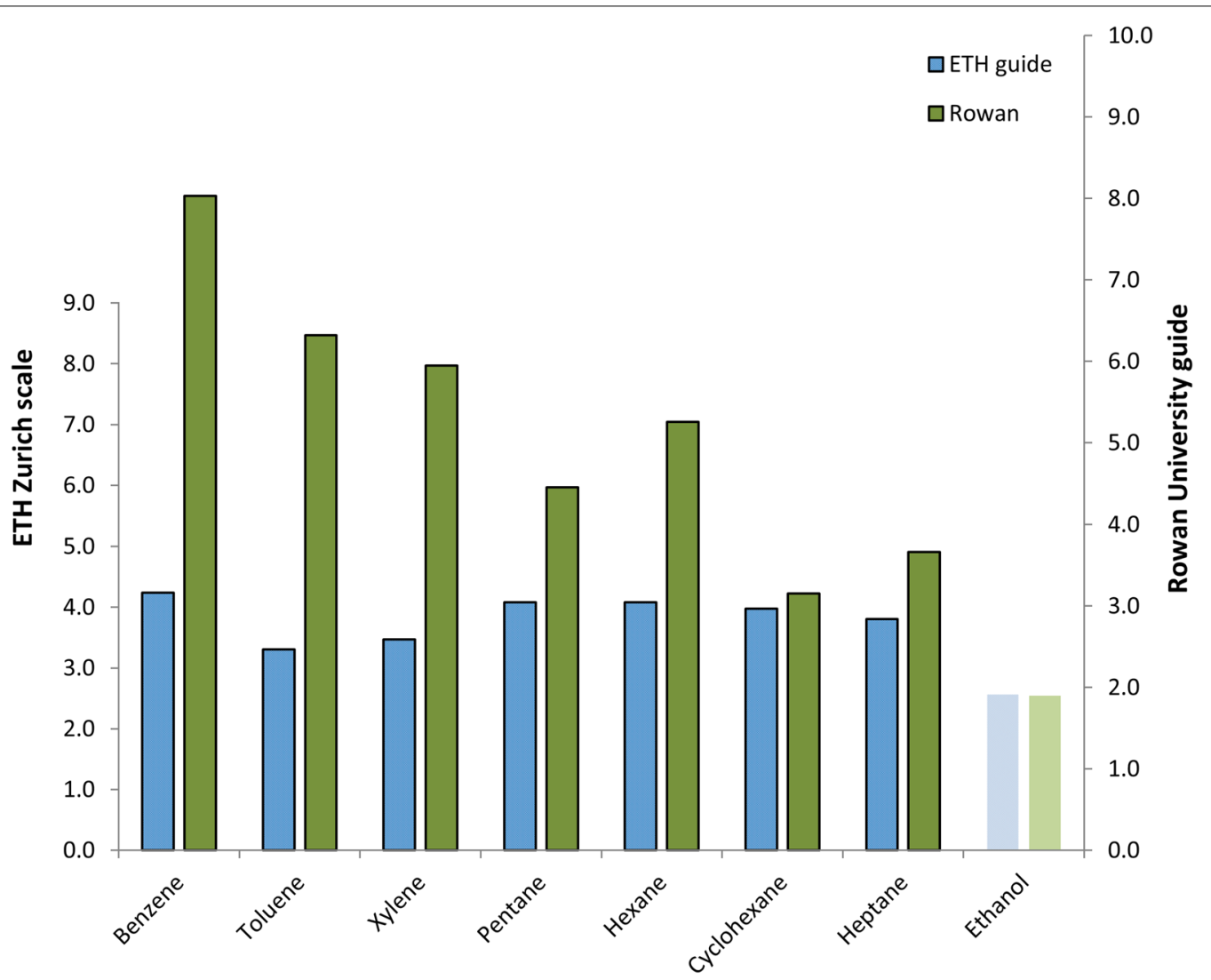

Fig. 5 The greenness of conventional hydrocarbon solvents relative to ethanol 
approach developed by ETH Zurich is unable to make any meaningful distinction between the greenness of the hydrocarbons, the Rowan University assessment offers greater variance across this set. Accordingly cyclohexane and $n$-heptane are considered to be greener than $n$-pentane and $n$-hexane, and the greenness of aromatic solvents increases with methyl group substitution.

\section{Solvent selection for exploratory chemistry}

The general concept of creating rankings of solvent greenness has taken a different direction within the chemical industries. The pharmaceutical sector in particular has been keen to establish their own institutional hierarchies of solvent greenness since the realisation that the solvent is the major component of a typical reaction in the manufacture of an active pharmaceutical ingredient [7]. As a consequence process solvents are responsible for the majority of energy use, waste, and greenhouse gas emissions [40]. This makes the minimisation of solvent use and greener substitutions a priority, and is often an easy target in green chemistry initiatives [41]. Although solvent-less chemistry has always been of interest to green chemists [42, 43], it is not generally applicable to the synthesis of pharmaceuticals and other fine chemicals. The solvent can have a profound influence on reaction rates and product selectivity [44], and the more general benefits of solvent use in reactions should not be overlooked either. Solvents act as a heat sink and a temperature regulator, lower mixture viscosity and improve mass transfer, and make selective extractions and separations possible $[31,45]$.

Solvent selection tools do not always require the user to perform calculations and compare numerical ranking systems. Alternative solvents with low toxicity, minimal safety concerns and little impact on the environment can be selected from simple visual aids [46-48]. Even mobile phone apps are now available for this purpose [49]. Solvent selection guides designed for the small scale chemistry labs of the pharmaceutical industry tend to be lists of solvents arranged according to company usage policy. Compared to the ETH Zurich and Rowan University tools, there is a clearer correlation between the solvents restricted by regulations (Tables 1,2 ) and the recommendations of pharmaceutical industry solvent selection guides. Three prominent guides developed for medicinal chemistry have been combined for the purpose of comparison in this work (Figs. 6, 7). The colour coding is a universally used 'traffic light' system, with the comment on each solvent specific to the conditions imposed by each company. So where Pfizer might consider a solvent to be 'usable', GSK state it has 'some issues' and Sanofi would suggest 'substitution advisable' (e.g., as is the case for toluene). Figures 6 and 7 are shortened to only include solvents with at least two entries in the Pfizer, GSK and Sanofi medicinal chemistry solvent selection guides. An expanded version containing all the solvents featured in the three tools is presented as an additional file (Additional file 1).

Pfizer were the first company to publish their colourcoded, hierarchical solvent selection guide for medicinal chemists [48]. The tool is a simple document listing solvents as 'preferred,' 'usable', or 'undesirable' (refer to Figs. 6, 7; Additional file 1). Pfizer have prioritised userfriendliness in making this solvent selection guide, if only to encourage chemists to use it. As a result it could be considered that this tool is limited and unadventurous, but by promoting small changes that few would find disruptive to their work, a large benefit can be felt company-wide. As an accompaniment to the Pfizer solvent selection guide, a useful substitution guide is provided for those solvents regarded as undesirable (Table 3). In this accompanying tool they suggest DCM as a replacement for other chlorinated solvents in cases when a non-chlorinated solvent is not applicable. Although this is by no means an ideal conclusion, by introducing this tool in their medicinal chemistry labs, Pfizer actually reported a $50 \%$ reduction in chlorinated solvent use over 2 years, and achieved a $97 \%$ reduction in undesirable ethers (diisopropyl ether especially). They also observed increased use of $n$-heptane in place of the neurotoxic $n$-hexane and the more volatile and flammable $n$-pentane. Therefore it can be concluded that by simply increasing awareness of solvent issues, management can guide bench chemists towards greener solvent use with the simplest of solvent selection aids.

GlaxoSmithKline (GSK) had already been producing solvent selection guides for process chemists by the time the Pfizer medicinal chemistry tool was published $[37,40]$. GSK then followed suit with a simplified solvent selection guide for medicinal chemistry laboratories themselves, derived from an updated and expanded solvent assessment [46]. The methodology is more multifaceted that the Pfizer tool, with a detailed breakdown of scores for different EHS categories freely available as supplementary information to the main article [50]. The one notable difference between the Pfizer and GSK ratings of solvent greenness is for methyl ethyl ketone (MEK), which is preferred to Pfizer but is considered to have major issues for GSK (Fig. 7). To clarify, MEK does have serious environmental consequences [51], but is safe to handle with low toxicity [46]. The contrast between its EHS properties is probably the reason for the different interpretations of the two solvent selection guides, with the Pfizer tool weighted more towards health and safety. The data behind the GSK medicinal chemistry solvent selection guide is also used by process development 


\begin{tabular}{|c|c|c|c|c|}
\hline Class & Solvent & $\begin{array}{l}\text { Conclusion } \\
\text { (Pfizer) }\end{array}$ & $\begin{array}{l}\text { Conclusion } \\
\text { (GSK) }\end{array}$ & Conclusion (Sanofi) \\
\hline \multirow[t]{9}{*}{ Alcohols } & \multirow{9}{*}{$\begin{array}{l}\text { Methanol } \\
\text { Ethanol } \\
\text { 1-Propanol } \\
\text { i-Propanol } \\
\text { 1-Butanol } \\
\text { 2-Butanol } \\
\text { t-Butanol } \\
\text { Ethylene glycol } \\
\text { 2-Methoxyethanol }\end{array}$} & Preferred & Some issues & Recommended \\
\hline & & Preferred & Some issues & Recommended \\
\hline & & Preferred & Some issues & Recommended \\
\hline & & Preferred & Some issues & Recommended \\
\hline & & Preferred & Few issues & Recommended \\
\hline & & & Few issues & Recommended \\
\hline & & Preferred & \multirow[t]{2}{*}{ Some issues } & Substitution advisable \\
\hline & & \multirow[t]{2}{*}{ Usable } & & Substitution advisable \\
\hline & & & Major issues & Substitution requested \\
\hline \multirow{9}{*}{$\begin{array}{l}\text { Hydro- } \\
\text { carbons }\end{array}$} & \multirow{9}{*}{$\begin{array}{l}n \text {-Pentane } \\
\text { Hexane(s) } \\
\text { Cyclohexane } \\
\text { Methylcyclohexane } \\
\text { Heptane } \\
\text { Isooctane } \\
\text { Benzene } \\
\text { Toluene } \\
\text { Xylene(s) }\end{array}$} & Undesirable & & Banned \\
\hline & & Undesirable & Major issues & Substitution requested \\
\hline & & Usable & Some issues & Substitution advisable \\
\hline & & Usable & & Substitution advisable** \\
\hline & & Usable & Some issues & Substitution advisable \\
\hline & & Usable & Some issues & \\
\hline & & Undesirable & Major issues & \\
\hline & & Usable & Some issues & Substitution advisable \\
\hline & & Usable & Some issues & Substitution advisable \\
\hline \multirow{5}{*}{$\begin{array}{l}\text { Dipolar } \\
\text { aprotic }\end{array}$} & \multirow{5}{*}{$\begin{array}{l}\text { DMSO } \\
\text { Acetonitrile } \\
\text { DMF } \\
\text { DMAc* } \\
\text { NMP }\end{array}$} & Usable & Some issues & Substitution advisable \\
\hline & & Usable & Major issues & Recommended \\
\hline & & Undesirable & Major issues & Substitution requested \\
\hline & & Undesirable & Major issues & Substitution requested \\
\hline & & Undesirable & Major issues & Substitution requested \\
\hline \multicolumn{5}{|c|}{$\begin{array}{l}\text { * Listed as 'dimethyl acetate' in the original Pfizer publication [45]. } \\
\text { **Coloured yellow but in the original Sanfoni publication accompanied with the comment } \\
\text { reserved for red shaded entries 'substitution requested' [44]. }\end{array}$} \\
\hline
\end{tabular}

Fig. 6 Unified version of general solvent selection guides for medicinal chemists (part 1) [46-48]

scientists, and accordingly includes more environmental parameters.

More recently Sanofi have also offered an equivalent solvent selection guide [47]. The tool has evolved from an early version of the company's internal solvent selection guide which divided solvents into a recommended list and a substitution list. Chemists developing synthetic routes had to justify the use of solvents on the substitution list by proving no alternatives work as effectively. However the substitution list was very long and unwieldly, as reported by the authors [47]. Therefore a new tool was developed, providing a reference card for each solvent containing useful property data. A solvent selection table for each class of solvent with an overall recommendation for each solvent is complemented by their expected constraints and associated hazard warnings. The Sanofi solvent selection guide contains many more solvents than feature in the Pfizer and GSK 


\begin{tabular}{|c|c|c|c|c|}
\hline Class & Solvent & $\begin{array}{l}\text { Conclusion } \\
\text { (Pfizer) }\end{array}$ & $\begin{array}{l}\text { Conclusion } \\
\text { (GSK) }\end{array}$ & Conclusion (Sanofi) \\
\hline \multirow[t]{4}{*}{ Esters } & \multirow{4}{*}{$\begin{array}{l}\text { Methyl acetate } \\
\text { Ethyl acetate } \\
n \text {-Propyl acetate } \\
i \text {-Propyl acetate }\end{array}$} & & Some issues & Substitution advisable \\
\hline & & Preferred & Some issues & Recommended \\
\hline & & & Few issues & Recommended \\
\hline & & Preferred & Few issues & Recommended \\
\hline \multirow[t]{8}{*}{ Ethers } & \multirow{8}{*}{$\begin{array}{l}\text { THF } \\
\text { 2-MeTHF } \\
\text { TBME } \\
\text { CPME } \\
\text { Diethyl ether } \\
\text { Di-i-propyl ether } \\
\text { 1,2-DME } \\
\text { 1,4-Dioxane }\end{array}$} & \multirow{4}{*}{$\begin{array}{l}\text { Usable } \\
\text { Usable } \\
\text { Usable }\end{array}$} & Major issues & Substitution advisable \\
\hline & & & \multirow{3}{*}{$\begin{array}{l}\text { Some issues } \\
\text { Some issues } \\
\text { Some issues }\end{array}$} & Recommended \\
\hline & & & & Substitution advisable \\
\hline & & & & Substitution requested \\
\hline & & Undesirable & Major issues & \\
\hline & & Undesirable & Major issues & Substitution advisable \\
\hline & & Undesirable & Major issues & Substitution requested \\
\hline & & Undesirable & Major issues & Substitution requested \\
\hline \multirow[t]{3}{*}{ Ketones } & \multirow{3}{*}{$\begin{array}{l}\text { Acetone } \\
\text { Methylethyl ketone } \\
\text { MIBK }\end{array}$} & Preferred & Some issues & Recommended \\
\hline & & Preferred & Major issues & Recommended \\
\hline & & & Some issues & Recommended \\
\hline \multirow{4}{*}{$\begin{array}{l}\text { Halo- } \\
\text { genated }\end{array}$} & \multirow{4}{*}{$\begin{array}{l}\text { Dichloromethane } \\
\text { 1,2-Dichloroethane } \\
\text { Chloroform } \\
\mathrm{CCl}_{4}\end{array}$} & Undesirable & Major issues & Substitution advisable \\
\hline & & Undesirable & Major issues & \\
\hline & & Undesirable & Major issues & \\
\hline & & Undesirable & Major issues & \\
\hline \multirow{3}{*}{$\begin{array}{l}\text { Miscellan- } \\
\text { eous }\end{array}$} & \multirow{3}{*}{$\begin{array}{l}\text { Water } \\
\text { Acetic acid } \\
\text { Pyridine }\end{array}$} & Preferred & Few issues & Recommended \\
\hline & & Usable & & Substitution advisable \\
\hline & & Undesirable & & Substitution advisable \\
\hline
\end{tabular}

Fig. 7 Unified version of general solvent selection guides for medicinal chemists (part 2) [46-48]

medicinal chemistry tools. The overall conclusion for each solvent has been given in previously in Figs. 6 and 7 (for an expanded version refer to the Additional file 1). The following reduced dataset of just dipolar aprotic solvents demonstrates the detail of the Sanofi solvent selection guide (Fig. 8). The familiar traffic light colour coding is used, with additional indicators. The residual solvent limits for pharmaceuticals according to the International Conference on Harmonisation (ICH) are used [52].

The use of legislative categories makes the Sanofi solvent selection guide industrially relevant, directed by necessity above any personal perception of what a green solvent actually is. The overall ranking and the listing of other concerns makes the tool helpful to users in exploratory chemistry laboratories who may not be directly confronted with the regulatory constraints of solvent use. Substitution is required for the amide solvents in Fig. 8, with acetonitrile the only recommended solvent that could be used instead. The lack of options for green dipolar aprotics is evident, even acetonitrile is not considered as a green solvent in other solvent selection guides [46, 48]. For higher temperature reactions dimethyl sulphoxide (DMSO) and sulpholane might be acceptable options, although substitution is advised.

The data collated from the Pfizer, GSK, and Sanofi solvent selection guides produces a number of conclusions. The greenest solvents (i.e., those with three green shaded entries or two green entries and a blank entry in Figs. 6 and 7) are water, $n$-propyl acetate, $i$-propyl acetate, 1-butanol and 2-butanol. This set is severely limited, 
Table 3 Pfizer solvent replacement table [48]

\begin{tabular}{lll}
\hline Solvent & Issues & Alternatives \\
\hline Pentane & Lower flash point than other similar solvents & Heptane \\
Diethyl ether & Lower flash point than other similar solvents & 2-MeTHF, TBME \\
Diisopropyl ether & Powerful peroxide formation compared to similar solvents & 2-MeTHF, TBME \\
Hexane(s) & More toxic than other similar solvents & Heptane \\
Benzene & Carcinogen & Toluene \\
Chloroform & Carcinogen & DCM \\
1,2-DCE & Carcinogen & DCM \\
$1,2-$ DME & Carcinogen & 2-MeTHF, TBME \\
Pyridine & Carcinogenicity (not classifiable) & Triethylamine (base) \\
$1,4-$ Dioxane & Carcinogenicity (not classifiable) & 2-MeTHF, TBME \\
DCM & Emissions & Application dependant \\
Carbon tetrachloride & Emissions & DCM \\
DMF & Reproductive toxicity & Acetonitrile \\
DMAc & Reproductive toxicity & Acetonitrile \\
NMP & Reproductive toxicity & Acetonitrile \\
\hline
\end{tabular}

\begin{tabular}{|c|c|c|c|c|c|c|}
\hline Solvent & Overall ranking & $\begin{array}{l}\mathrm{ICH} \\
\text { limit } \\
(\mathrm{ppm})\end{array}$ & Health* & Safety* & $\begin{array}{l}\text { Environ } \\
\text {-ment* }\end{array}$ & Other concerns \\
\hline DMSO & $\begin{array}{l}\text { Substitution } \\
\text { advisable }\end{array}$ & 5000 & G & Y & G & $\begin{array}{l}\text { Many incompati- } \\
\text { bilities, odor. }\end{array}$ \\
\hline Sulpholane & $\begin{array}{l}\text { Substitution } \\
\text { advisable }\end{array}$ & 160 & G & G & G & $\begin{array}{l}\text { High boiling and } \\
\text { freezing points. }\end{array}$ \\
\hline Acetonitrile & Recommended & 410 & Y & Y & G & Availability. \\
\hline DMF & $\begin{array}{l}\text { Substitution } \\
\text { requested }\end{array}$ & 880 & $\mathrm{R}$ & G & G & CMR (reprotoxic). \\
\hline DMAc & $\begin{array}{l}\text { Substitution } \\
\text { requested }\end{array}$ & 1090 & $\mathrm{R}$ & G & G & CMR (reprotoxic). \\
\hline NMP & $\begin{array}{l}\text { Substitution } \\
\text { requested }\end{array}$ & 530 & $\mathrm{R}$ & Y & G & $\begin{array}{l}\text { CMR (reprotoxic), } \\
\text { high boiling point. }\end{array}$ \\
\hline DMPU & $\begin{array}{l}\text { Substitution } \\
\text { advisable }\end{array}$ & $\begin{array}{l}\text { Not } \\
\text { listed }\end{array}$ & Y & Y & G & $\begin{array}{l}\text { Hygroscopic, high } \\
\text { boiling point, cost. }\end{array}$ \\
\hline
\end{tabular}

Fig. 8 Sanofi solvent selection guide for selected dipolar aprotic solvents

with only alcohols and esters featuring alongside water as being recognised across the board as green solvents. This conclusion is in agreement with the ETH Zurich and Rowan University tools. Conclusions can also be drawn regarding the least desirable solvents. The following solvents are unequivocally considered as undesirable if not already banned (i.e., at least two red or black shaded entries in Figs. 6 and 7, no yellow or green entries): 
chloroform, 1,2-DCE, carbon tetrachloride, NMP, DMF, DMAc, benzene, hexane, 1,4-dioxane, 1,2-DME, diethyl ether, and 2-methoxyethanol. This set rules out many of the dipolar aprotic, chlorinated, hydrocarbon and ether solvents. Chemists should be careful when using these types of solvent and consider the EHS implications of their choice. 2-Methyltetrahydrofuran (2-MeTHF) and tert-butyl methyl ether (TBME) are preferable to THF and diethyl ether in this regard. Where there are no green options within a solvent class it is clear that only under unusual circumstances could one of the green solvents noted above replace the red or black-listed solvents without a substantial re-engineering of the process. As an added complication the three solvent selection guides shown in Figs. 6 and 7 do not always agree. For example acetonitrile reaches a different outcome in each of the solvent selection guides.

\section{Scoring solvents for greener chemistry}

The simple three-tiered and colour coded approach to categorising solvents for medicinal chemistry purposes has the advantage of easy interpretation but at the expense of limiting the depth of information provided. When designing larger scale reactions, more information is needed about each solvent as the process is geared towards commercial scale manufacturing, where any concerns over EHS issues are magnified. GlaxoSmithKline (GSK) was the first pharmaceutical company to publish a solvent selection guide intended for use in process development $[37,40]$. In its original presentation, each of the 35 featured solvents has a relative ranking from 1 (ungreen) to 10 (green) in four categories of waste, environmental impact, health, and safety [37]. A number of parameters are considered within each category. For example, the waste category incorporates incineration, solvent recovery, and biological waste treatments. The solvent properties that affect incineration are its heat of combustion, the possibility of $\mathrm{HCl}$ or dioxin formation or $\mathrm{NO}_{\mathrm{X}}$ and $\mathrm{SO}_{\mathrm{X}}$ emissions, and its water solubility (Fig. 9). A complete list of categories is presented in the accompanying additional file (Additional file 1). The approach was later expanded to contain a fifth category on life cycle assessment [40].

Upon publication of their medicinal chemistry solvent selection guide GSK added a new reactivity/stability score and legislative flags to indicate where controls exist for solvent use [46]. A much abbreviated version of the latest GSK categorisation has been provided as Fig. 10, listing just the dipolar aprotic solvents as an example of a difficult to replace class of solvent. The categories are waste, environmental impact, health, flammability, reactivity, and life cycle assessment (LCA). Legislative controls are also indicated in the form of 'flags' in Fig. 10. The scoring system highlights the safe to use but toxic nature of the dipolar aprotic solvents. Because of the contrast between the separate scores, this sort of data representation is more helpful than a single EHS indicator. The ETH Zurich and Rowan University approaches can provide a misleading 'average' score in this case. The greater detail from separated scores also resolves the ambiguity of the colour coded three tier assessments provided in Figs. 6 and 7.

The decisions reached in the GSK tools are not immovable verdicts but dynamic and altering in the face of new information and changing company policy. Indeed the scores attributed to each solvent have changed over time [53]. The approach used by GSK utilises the geometric mean of the properties that make up each category to establish the numerical scale for each EHS score. A lower limit and an upper limit are defined so that the 1-10 scale is not stretched too far by outliers, which would clump most solvents in the middle of the scale (Fig. 11) [40]. This means the EHS scores are dependent on what solvents are included in the assessment, which is at risk of a purposely created bias, and will change as new solvents are added. The benefit of this calculation is that the final scoring is otherwise not subjective, and a useful spread of scores is obtained from 1 to 10 .

The concept of providing numerical scores to an EHS profile of solvents has proven to be popular, and subsequently repeated by other institutions. The American Chemical Society (ACS) Green Chemistry Institute's

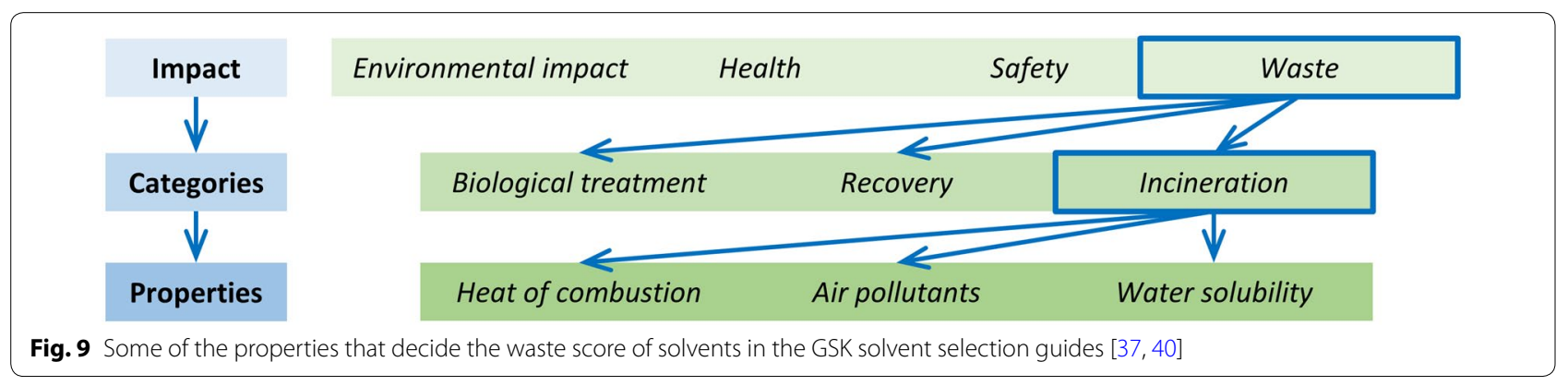




\begin{tabular}{|c|c|c|c|c|c|c|c|}
\hline Solvent & Waste & $\begin{array}{l}\text { Environ. } \\
\text { impact }\end{array}$ & Health & Flamm. & React. & LCA & Flag \\
\hline \multirow{7}{*}{$\begin{array}{l}\text { DMSO } \\
\text { Sulpholane } \\
\text { Acetonitrile } \\
\text { DMF } \\
\text { DMAC } \\
\text { NMP } \\
\text { DMPU }\end{array}$} & 5 & 5 & 7 & 9 & 2 & 6 & $\mathrm{n} / \mathrm{a}$ \\
\hline & 5 & 9 & 6 & 10 & 10 & $\mathrm{n} / \mathrm{a}$ & $\mathrm{n} / \mathrm{a}$ \\
\hline & 2 & 6 & 6 & 6 & 10 & 3 & $\mathrm{n} / \mathrm{a}$ \\
\hline & 4 & 6 & 2 & 9 & 9 & 7 & $*$ \\
\hline & 5 & 6 & 2 & 10 & 8 & 2 & $*$ \\
\hline & 5 & 6 & 3 & 9 & 8 & 4 & $*$ \\
\hline & 7 & 7 & 4 & 9 & 7 & 3 & $n / a$ \\
\hline
\end{tabular}

Fig. 10 Excerpt of the GSK solvent selection guide (dipolar aprotic solvents)

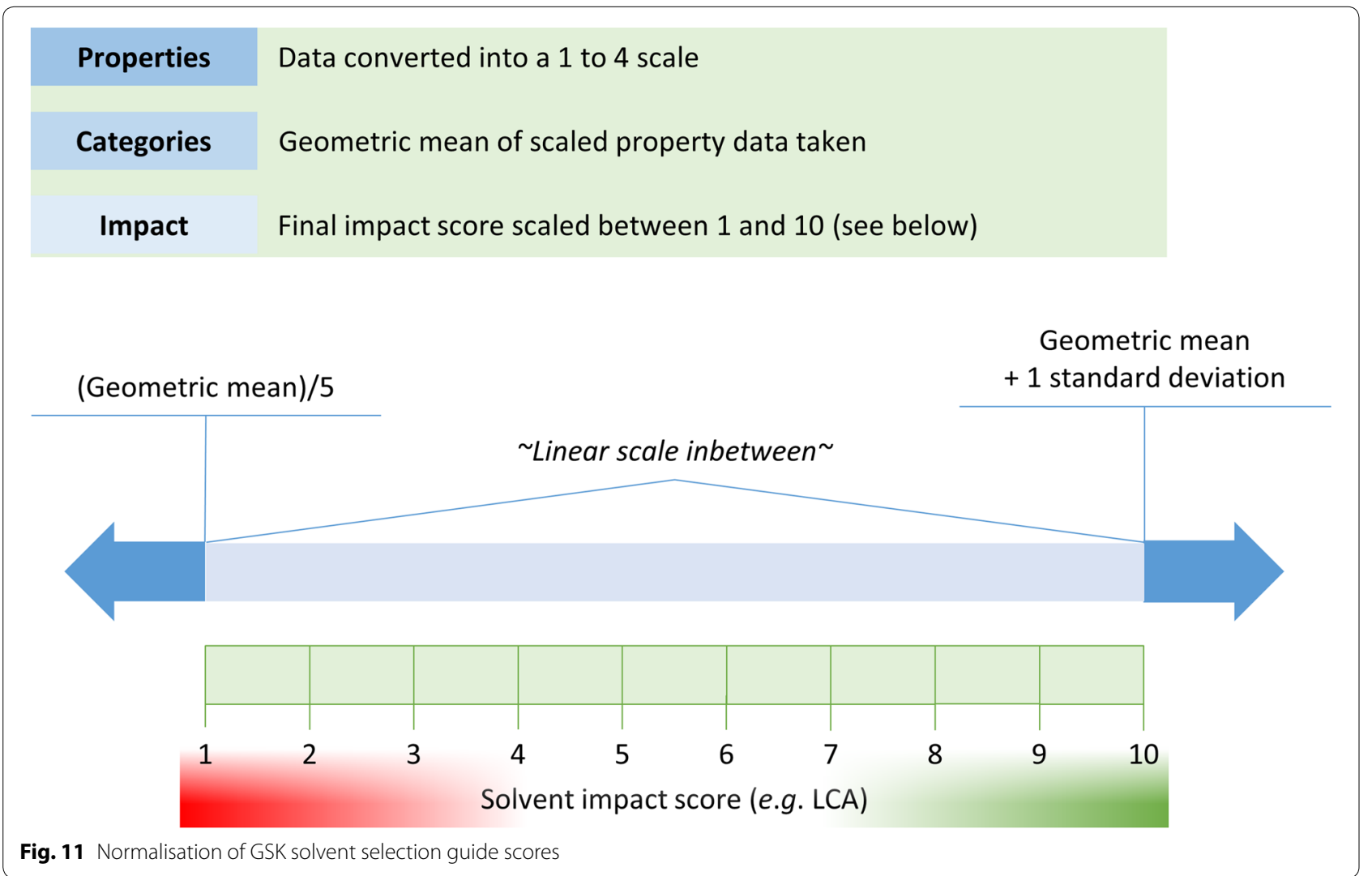

(GCI) Pharmaceutical Roundtable was initiated in 2005, uniting 14 partner organisations with the purpose of setting common goals and standards in relation to green chemistry practices. Together they developed a solvent selection guide [54], using the familiar numerical scoring and colour coding from the GSK solvent selection guide and the unpublished AstraZeneca equivalent [55].
It has also been transformed into a mobile phone app [49]. There is one health and one safety category in the ACS GCI solvent selection guide, accompanied by three environmental criteria. The assessment for the dipolar aprotic solvents is presented as Fig. 12, providing a comparison to earlier solvent selection tables (Figs. 8, 10). Note the scoring is reversed compared to the GSK 


\begin{tabular}{|l|l|l|l|l|l|}
\hline Solvent & Safety & Health & Air & Water & Waste \\
\hline DMSO & 3 & 4 & 4 & 4 & 8 \\
\cline { 2 - 6 } \multirow{3}{*}{$\begin{array}{l}\text { Sulpholane } \\
\text { DCetonitrile }\end{array}$} & 2 & 3 & n/a & 5 & 8 \\
\cline { 2 - 6 } & 3 & 5 & 6 & 4 & 6 \\
\cline { 2 - 6 } DMAC & 3 & 7 & 3 & 2 & 7 \\
\cline { 2 - 6 } & 2 & 7 & 3 & 7 & 7 \\
\cline { 2 - 6 } & 3 & 6 & 6 & 2 & 7 \\
\hline
\end{tabular}

Fig. 12 Excerpt of the ACS GCl solvent selection guide (dipolar aprotic solvents)

tool. Nevertheless the distribution of colour coding is the same, with the three worst possible scores $(8,9$, and 10$)$ shaded in red, and the ideal scores $(1,2$, and 3$)$ in green. The remaining options are coloured in yellow. Inspection of the complete ACS GCI guide reveals in general there are very few red (i.e., ungreen) scores [54], a fact that is repeated in Fig. 12 also. Sulphur containing solvents are penalised for the $\mathrm{SO}_{\mathrm{X}}$ emissions generated upon incineration. Several ether solvents have poor safety or health scores but for the most part this tool can be considered as more forgiving than the GSK solvent selection guide for example. For instance the health score does not appear to incorporate chronic toxicity, which is a cause for concern for NMP, DMF and DMAc (Table 2). The lack of information behind the assignments given in the ACS GCI solvent selection guide does raise questions, but this is a common concern and only fully alleviated by the interactive tools developed by ETH Zurich and Rowan University, which themselves also misrepresent the common amide solvents DMF, DMAc, and NMP as green solvents.

It could be argued that the many categories of the GSK and ACS GCI tools, each with a numerical scale derived from various parameters, make it too difficult to balance these different aspects and reach a firm conclusion. The thresholds that define the different colour coded scores are established according to the preference of the guide's designers and may not be consistent between tools or relevant to regulations. A response to this is presented in a more recent attempt at a solvent selection guide with a greater emphasis on regulatory controls. This tool has been constructed by scientists from Sanofi, GSK, Pfizer, the University of York, and Charnwood consultants as part of a collaborative research project known as the CHEM21, a public-private partnership under the innovative medicines initiative (IMI) [56]. The approach used to assign solvent greenness is strongly derived from the Global Harmonized System (GHS) of classification, labelling and packaging (CLP) of substances [29]. The methodology is openly available as supplementary information to the article and can be used as desired to extend and tailor the assessment to new solvents. Thus this recent development shows a clear evolution from the ETH Zurich tool, again based on hazard codes and the physical properties of solvents, but updated to match the most recent chemical regulations. A key difference is that the final ranking of each solvent in the CHEM21 guide is derived from its least green characteristic, not an average or summation of unrelated properties. The scale has an upper limit of ten as the worst score, but in a change to previous tools a score of seven is now shaded in red. Additionally a phrase is associated to each solvent, as is the case with the simplified medicinal chemistry solvent selection guides of Pfizer, Sanofi and GSK. This means a detailed examination of the tool is not always needed in order to use it. However the usefulness and accuracy of this summarising statement is questionable given that the project consortium responsible has overruled the data-led methodology on occasion. This can be seen for acetonitrile and DMSO in the following excerpt of just dipolar aprotic solvents (Fig. 13). This highlights that solvent selection can never be an exact science, and an organisational preference for certain solvents will influence each designation, just as a chemist's past experience with solvents has historically determined their own solvent selection on a personal basis. However, by deriving a solvent selection guide from experience and regulation, this tool is able to align solvent use with anticipated controls and restrictions on hazardous chemicals in the future, easing the transition to greener solvent use. Also note the health scores for amide solvents are more representative of their reprotoxicity than found in the ACS GCI solvent selection guide.

Members of the CHEM21 consortium have separately reviewed the conclusions of three solvent selection guides (GSK, AstraZeneca, ACS GCI) in an attempt to produce a consensus that later guided the development of their own guide as reviewed above [57]. Each tool was adapted into a three tiered assessment of safety, health, and environment impact. In this work, the outcome of the CHEM21 survey of solvent selection guides is supplemented with the Sanofi and newer CHEM21 solvent selection guides. The total of five tools can be arranged in terms of the EHS triple category format, concluded with an overall assessment. In Fig. 14, the colour shading is based on that of the original publications, with numbers removed because the scales are independent of each other. The outcome of the safety $(\mathrm{S})$, health $(\mathrm{H})$, and environment (E) categories, and the overall conclusion have been assigned according to the methodology of the CHEM21 survey in the case of the GSK, AstraZeneca and ACS GCI guides [57]. Green $(\mathrm{G})$, yellow $(\mathrm{Y})$ and red (R) entries in Fig. 14 are labelled as such. This does mean that conflicts between the original tools and the harmonised survey results do occur. For instance, acetonitrile is now concluded to be problematic (yellow category) 


\begin{tabular}{|c|c|c|c|c|c|}
\hline Solvent & Safety & Health & Environment & Conclusion* & $\begin{array}{l}\text { Revised } \\
\text { conclusion }\end{array}$ \\
\hline \multirow{7}{*}{$\begin{array}{l}\text { DMSO } \\
\text { Sulpholane } \\
\text { Acetonitrile } \\
\text { DMF } \\
\text { DMAC } \\
\text { NMP } \\
\text { DMPU }\end{array}$} & 1 & 1 & 5 & Recommended & Problematic \\
\hline & 1 & 9 & 7 & Hazardous & Not needed \\
\hline & 4 & 3 & 3 & Recommended & Problematic \\
\hline & 3 & 9 & 5 & Hazardous & Not needed \\
\hline & 1 & 9 & 5 & Hazardous & Not needed \\
\hline & 1 & 9 & 7 & Hazardous & Not needed \\
\hline & 1 & 6 & 7 & Problematic & Not needed \\
\hline \multicolumn{6}{|c|}{$\begin{array}{l}\text { *'Hazardous': one score of } 8 \text { or higher, or two scores between } 7 \text { and } 10 \text {. } \\
\text { 'Problematic': one score equal to } 7 \text {, or two scores between } 4 \text { and } 6 \text {. All other } \\
\text { solvents are recommended. }\end{array}$} \\
\hline
\end{tabular}

Fig. 13 Excerpt of the CHEM21 (conventional) solvent selection guide (dipolar aprotic solvents only)

within the GSK guide and overall. However acetonitrile was colour coded in red in the original GSK solvent selection guide, and considered to have major issues. The information in the original Sanofi and CHEM21 solvent selections guides could be used directly because both these tools are a triple EHS assessment with an overall conclusion for each solvent anyway. In the case of the Sanofi solvent selection guide, primarily the occupational health score has been used. If unavailable, the ICH concentration limit was used instead for the health category. Any revised conclusions in the CHEM21 tool appear to the right of the default conclusion. Here only the dipolar aprotic solvents are compared (Fig. 14), but a complete table is provided as an additional file (Additional file 1).

Interpreting Fig. 14, again it is evident that NMP, DMF and DMAc are not desirable solvent choices. The tools developed by AstraZeneca and the ACS GCI are less harsh in their assessment, but it is not clear why given the reproductive toxicity of the amide solvents. The method by which the AstraZeneca scores are converted for the survey of solvent selection guides rates NMP as greener than ethyl acetate [57]. This clearly highlights an inconsistency between the AstraZeneca approach to solvent selection and known chronic toxicity concerns, especially as NMP is a substance of very high concern is posed for restrictions on its use in Europe [30]. Despite its stability issues at high temperature DMSO seems to be a greener alternative. Sulpholane too had previously been recognised as an improved solvent choice over the reprotoxic dipolar aprotic solvents [58]. Sulpholane receives three green colour coded scores from Sanofi in its EHS assessment, yet only obtains an overall yellow ranking meaning 'substitution advisable'. This is because it has a moderate-to-low ICH concentration limit in pharmaceuticals $(160 \mathrm{ppm})$ and is further penalised for its high melting point and high boiling point [47]. Overall sulpholane is recommended as a solvent in the survey of solvent selection guides. Unfortunately sulpholane is now suspected to also be a reprotoxin, a fact reflected in the conclusions of the CHEM21 solvent selection guide (Fig. 13) [56]. Only the most recent safety datasheets contain this information and it is not widely known at the time of writing [59]. Despite being recommended as an alternative solvent decades before the solvent selection guides of the pharmaceutical industry existed, the urea derivative dimethyl propylene urea (DMPU) has not become a prominent green solvent, but may also be worth considering for certain types of chemistry $[60,61]$.

The findings of the CHEM21 consortium in their survey of solvent selection guides were used to produce a summary (Table 4) [57]. A consensus in the categorisation of solvents was not always found [57], hence the introduction of intermediate categories of 'recommended or problematic' and 'problematic or hazardous'. The inconclusive positioning of some solvents in this hierarchy is due to the different interpretations of what it means to be green. Overall the survey has been quite successful in determining a set of ideal solvents. The diversity of the greenest solvents is clearly limited, emphasising that new solvents must be designed to replace amides, chlorinated solvents and hydrocarbons especially. The one probable green alternative to amide solvents is sulpholane, but as previously discussed, more recent assessments are less approving (Fig. 13) [56]. 


\begin{tabular}{|c|c|c|c|c|c|c|}
\hline Solvent & & $S$ & $\mathrm{H}$ & $E$ & Conclusion & Survey result \\
\hline \multirow[t]{5}{*}{ DMSO } & GSK & $\mathrm{R}$ & $Y$ & Y & Y & \multirow[t]{5}{*}{ Problematic } \\
\hline & $A Z$ & G & G & $Y$ & G & \\
\hline & Sanofi & $\mathrm{Y}$ & $\bar{G}$ & $\bar{G}$ & $Y$ & \\
\hline & $A C S G C l$ & G & Y & $\mathrm{R}$ & Y & \\
\hline & CHEM21 & G & G & $Y$ & G & \\
\hline \multirow[t]{5}{*}{ Sulpholane } & GSK & G & Y & Y & G & \multirow[t]{5}{*}{ Recommended } \\
\hline & $A Z$ & G & G & Y & G & \\
\hline & Sanofi & G & G & $\mathrm{G}$ & $Y$ & \\
\hline & ACS GCl & $\bar{G}$ & $\mathrm{G}$ & $\overline{\mathrm{R}}$ & G & \\
\hline & CHEM21 & G & $\mathrm{R}$ & $\mathrm{R}$ & $\mathrm{R}$ & \\
\hline \multirow[t]{5}{*}{ Acetonitrile } & GSK & $Y$ & Y & $\mathrm{R}$ & $Y$ & \multirow[t]{5}{*}{ Problematic } \\
\hline & $A Z$ & Y & $\mathrm{R}$ & $\mathrm{R}$ & $\mathrm{R}$ & \\
\hline & Sanofi & $Y$ & $Y$ & $\mathrm{G}$ & G & \\
\hline & $A C S G C l$ & G & Y & $Y$ & G & \\
\hline & CHEM21 & $\mathrm{Y}$ & $\mathrm{G}$ & $\overline{\mathrm{G}}$ & G & \\
\hline \multirow[t]{5}{*}{ DMF } & GSK & $\mathrm{G}$ & $\mathrm{R}$ & $Y$ & $\mathrm{R}$ & \multirow[t]{5}{*}{ Hazardous } \\
\hline & $A Z$ & G & $\mathrm{R}$ & $\mathrm{R}$ & $Y$ & \\
\hline & Sanofi & G & $\mathrm{R}$ & G & $\mathrm{R}$ & \\
\hline & $A C S G C l$ & $\mathrm{G}$ & $Y$ & $Y$ & Y & \\
\hline & CHEM21 & $G$ & $\bar{R}$ & $Y$ & $R$ & \\
\hline \multirow[t]{5}{*}{ DMAC } & GSK & G & $\mathrm{R}$ & $\mathrm{R}$ & $\mathrm{R}$ & \multirow[t]{5}{*}{ Hazardous } \\
\hline & $A Z$ & $\mathrm{G}$ & $\mathrm{R}$ & $\mathrm{R}$ & Y & \\
\hline & Sanofi & $\mathrm{G}$ & $\bar{R}$ & $\bar{G}$ & $R$ & \\
\hline & $A C S G C I$ & G & Y & $Y$ & Y & \\
\hline & CHEM21 & $\mathrm{G}$ & $\mathrm{R}$ & $Y$ & $\mathrm{R}$ & \\
\hline \multirow[t]{5}{*}{ NMP } & GSK & $\mathrm{G}$ & 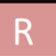 & $Y$ & $\mathrm{R}$ & \multirow[t]{5}{*}{ Hazardous } \\
\hline & $A Z$ & G & $\mathrm{R}$ & $\mathrm{R}$ & G & \\
\hline & Sanofi & $\mathrm{Y}$ & $\mathrm{R}$ & G & $\mathrm{R}$ & \\
\hline & $A C S G C l$ & G & Y & Y & Y & \\
\hline & CHEM 21 & $\mathrm{G}$ & $\mathrm{R}$ & $\mathrm{R}$ & $R$ & \\
\hline \multirow[t]{5}{*}{ DMPU } & GSK & $Y$ & $Y$ & $\mathrm{R}$ & \multirow[t]{4}{*}{ Y } & \multirow[t]{5}{*}{ Problematic } \\
\hline & $A Z$ & & & & & \\
\hline & Sanofi & $Y$ & Y & G & & \\
\hline & $A C S G C l$ & & & & & \\
\hline & CHEM21 & G & Y & $\mathrm{R}$ & Y & \\
\hline
\end{tabular}

Fig. 14 Simplified environmental $(E)$ health $(H)$ and safety $(S)$ rankings for dipolar aprotic solvents $[54,56,57]$ 


\section{Category}

Recommended

Inbetween recommended and problematic

\section{Problematic}

\section{Inbetween problematic and hazardous}

Hazardous

Highly hazardous<smiles>ClC(Cl)C(Cl)(Cl)Cl</smiles><smiles>CCCCCCC</smiles><smiles>CC1CCCO1</smiles><smiles>O=CO</smiles><smiles>COC(C)(C)C</smiles><smiles>CCN(C)CC</smiles><smiles>CN(C)C=O</smiles><smiles>CC(C)OC(C)C</smiles>

\section{Solvents $^{\mathrm{a}}$}<smiles>CCCCCOC(C)=O</smiles><smiles>Clc1ccccc1</smiles><smiles>CC#N</smiles><smiles>CC1CCCCC1</smiles><smiles>CS(C)=O</smiles><smiles>ClCCl</smiles><smiles>C1CCCCC1</smiles><smiles>c1ccncc1</smiles><smiles>CC(=O)N(C)C</smiles><smiles>CN1CCCC1=O</smiles><smiles>COCCO</smiles><smiles>CCCCCC</smiles><smiles>C1COCCO1</smiles><smiles>COCCOC</smiles><smiles>O=C([O-])[N+](=O)[O-]</smiles><smiles>c1ccccc1</smiles><smiles>CCOCC</smiles>

a Compound names are given in Table 5

The lack of breadth to the existing catalogue of green solvents is reiterated in another recent attempt to summarise different solvent selection guides [53]. Here, only some acids, alcohols, esters and ethers (and sulpholane) are denoted as green. The methodology behind the assessment of Eastman et al. is based on the GSK, Pfizer and Sanofi solvent selection guides but no further information was provided, and therefore it is not examined in depth as part of this work [53].

\section{Sources of solvents}

A key issue conspicuously absent from almost all solvent selection guides is the origin of each solvent. The ETH Zurich tool for calculating CED of solvent production 
does directly address this [32], but is limited to conventional petrochemical solvents [33]. For reviews on the topic of bio-based solvents, see the following references [4, 62-64]. Renewable feedstocks will need to be embraced to secure the sustainability of the chemical industry [5]. Solvent selection guides have become a vital component in the effort to enhance the greenness of the fine chemical industries, but few attempts have been made to highlight the renewability of solvents or simply just to incorporate solvents of a bio-based origin within these tools $[56,65,66]$. In addition to ethanol (which is now primarily made from biomass because of its energy uses) [67], and DMSO (made by oxidising the dimethyl sulphide by-product of wood pulping operations) [47], 2-MeTHF is presently the only prevalent example of a neoteric (meaning structurally novel or unconventional) bio-based solvent to feature across solvent selection guides [68]. Although the vast majority of solvents are produced from fossil resources, any progress in green solvent selection is short sighted unless renewable solvents are considered on an equal footing. The unconventional functionality of neoteric solvents can offer the same properties as conventional solvents but avoid the drawbacks of familiar chemical moieties such as the reprotoxic amides [69, 70]. Please note the general definition of a neoteric solvent also extends to ionic liquids [71], aqueous solvent systems [72], supercritical fluids [73], and tunable solvent systems [74], without relating to the origin of the solvent. However these types of solvent are not yet found in solvent selection guides.

Solvent selection guides can be modified to identify which solvents can be made from biomass, and how realistic a change in feedstock to biomass is, by considering any technological challenges or economical barriers. To demonstrate this, the collated solvent selection guide devised by Prat et al., summarising their 'survey of solvent selection guides' as shown in Table 4 [57], has been divided into categories of different solvent origins for the purpose of this work (Table 5). The column of bio-based solvents consists of solvents produced from biomass on a large scale, if not exclusively. Water has been included as a bio-based solvent for convenience. Those solvents that have been indicated as 'can be renewably sourced' in Table 5 are available on the market, but biomass is not the primary feedstock. Solvents with the potential to be produced from biomass are assigned as such if derived

Table 5 A modified version of the conclusion to the survey of solvent selection guides [57]

\begin{tabular}{|c|c|c|c|c|}
\hline Category & Bio-based & Can be sourced renewably & Potential biomass feedstock & Not bio-based \\
\hline Recommended & $\begin{array}{l}\text { Ethanol }(4)^{\mathrm{a}} \\
\text { Water }\end{array}$ & $\begin{array}{l}\text { 1-Butanol } \\
\text { Ethyl acetate }(2)^{\text {a }}\end{array}$ & $\begin{array}{l}\text { 1-Butyl acetate } \\
\text { Isopropanol (1) } \\
\text { Isopropyl acetate }\end{array}$ & $\begin{array}{l}\text { Anisole } \\
\text { Sulpholane }\end{array}$ \\
\hline Inbetween recommended and problematic & & $\begin{array}{l}\text { Acetic acid }(9)^{\mathrm{a}} \\
\text { Acetone } \\
\text { Ethylene glycol } \\
\text { Methanol }(3)^{\mathrm{a}}\end{array}$ & $\begin{array}{l}\text { Acetic anhydride } \\
t \text {-Butanol } \\
\text { Methyl acetate } \\
\text { MIBK }\end{array}$ & $\begin{array}{l}\text { Benzyl alcohol } \\
\text { Cyclohexanone } \\
\text { MEK }\end{array}$ \\
\hline Problematic & $\begin{array}{l}\text { DMSO }\{12 \%\}^{b} \\
\text { 2-MeTHF }\end{array}$ & & & $\begin{array}{l}\text { Acetonitrile }(10)^{\mathrm{a}} \\
\mathrm{PhCl}\{2 \%\}^{\mathrm{b}} \\
\text { DMPU } \\
\text { Heptane }(5)^{\mathrm{a}} \\
\text { Methylcyclohexane } \\
\text { Toluene }(7)^{\mathrm{a}} \\
\text { Xylene(s) }\end{array}$ \\
\hline Inbetween problematic and hazardous & & $\operatorname{THF}(6)^{\mathrm{a}}$ & $\begin{array}{l}\text { Formic acid } \\
\text { TBME }\end{array}$ & $\begin{array}{l}\text { Cyclohexane } \\
\text { DCM }(8)^{a}\{48 \%\}^{b} \\
\text { Pyridine }\end{array}$ \\
\hline Hazardous & & Triethylamine & $\begin{array}{l}\text { 1,4-Dioxane }\{0 \%\}^{b} \\
1,2-D M E\{6 \%\}^{b} \\
\text { DMAc }\{12 \%\}^{b} \\
\text { DMF }\{31 \%\}^{b} \\
\text { Methoxyethanol } \\
\text { NMP }\{9 \%\}^{b}\end{array}$ & $\begin{array}{l}\text { Diisopropyl ether }\{7 \%\}^{b} \\
n \text {-Hexane }\{14 \%\}^{b} \\
\text { Pentane }\end{array}$ \\
\hline Highly hazardous & & & Diethyl ether $\{3 \%\}^{b}$ & $\begin{array}{l}\text { Benzene } \\
\text { Chloroform }\{2 \%\}^{b} \\
\text { Carbon tetrachloride } \\
\text { 1,2-DCE }\{4 \%\}^{b} \\
\text { Nitromethane }\end{array}$ \\
\hline
\end{tabular}

\footnotetext{
a The ranking of the top ten solvents used by GSK in pilot plant operations in 2005 have been provided in parentheses, excluding water [7]

b Usage of solvents of concern and dipolar aprotic solvents as reported in Organic Process Research and Development between 1997 and 2012 , presented as the percentage of papers containing reactions performed in each solvent [8]. Data is not available for greener solvents
} 
from: bio-methanol (or syngas), bio-ethanol (or bioethylene), bio-acetic acid, bio-1-butanol, bio-isobutanol (or bio-isobutene), and bio-acetone (also applicable as a potential precursor to isopropanol) [75]. These are all highly feasible, drop in bio-based substitutes that fit into the existing solvent production chains. Other readily available bio-based chemicals such as glycerol have not been listed because these have no bearing on the solvents featured in Table 5. The undesirable chlorinated solvents are grouped with the solvents that cannot be made from the suggested bio-based intermediates. These are not necessarily unrealistic bio-based solvents from a technological perspective (e.g., chlorination of bio-based methane), but there is no incentive for suppliers to produce and distribute regulated carcinogenic solvents from renewable feedstocks.

Combined with GSK solvent use data from 2005, Table 5 indicates a poor integration of bio-based solvents within the pharmaceutical industry at that time. Although it is pleasing to see a preference to use heptane instead of $n$-hexane, and acetonitrile instead of other dipolar aprotics, neither are bio-based. Similarly toluene and DCM are commonly used in place of other, even more hazardous aromatic and chlorinated solvents, but again these are non-renewable solvents under regulatory scrutiny as discussed previously. Much of this has to do with the lack of physicochemical and EHS data for new solvents, and as such a limited understanding of their greenness.

More promisingly, recent papers documenting process development procedures show an increased use of 2-MeTHF in large scale chemical synthesis [8]. Table 5 does indicate that greener solvents are available, and biobased solvents are well represented in the 'recommended' and 'inbetween recommended and problematic' categories. The readily available bio-based solvents tend to be protic solvents, but also esters, ketones, and ethers. This leaves a need for green and renewable hydrocarbon solvents and dipolar aprotic solvent in particular. Not indicated in Table 5 are unconventional routes to bio-based solvents. Developments in the conversion of biomass into aromatic base chemicals [76], and specialised routes to methyl ethyl ketone [77], and acetonitrile [78], mean that an increasingly diverse number of solvents have prospects of a renewable feedstock.

Two recently published solvent selection guides have now incorporated unconventional bio-based solvents, published online in the journal Green Chemistry within 2 weeks of each other [56, 65]. These tools were not designed for the purpose of describing the sustainability of the solvents, but by including bio-based solvents on an equal footing to conventional solvents some welcome progression is demonstrated. Firstly the CHEM21 project consortium has devised a second solvent selection guide, based on the same GHS-led methodology as before (Fig. 13), but now applied to neoteric solvents (Fig. 15) [56]. Again a score of seven is shaded in red. Although equally applicable to all solvents, this model frequently concludes neoteric solvents are 'problematic' because insufficient toxicological or ecological data is available (this is the default conclusion if data is lacking, and is apparent from the conclusions in Fig. 15). The authors behind this solvent selection guide encourage solvent suppliers to collect and publish data on their products, otherwise the unknown environmental $(\mathrm{E})$, health $(\mathrm{H})$ and safety (S) profile of new solvents will remain an obstacle. Reassuringly there are only a small number of red shaded scores in the health and safety criteria of the unconventional solvents. Specifically, these correspond to the safety of the low flash point ethers cyclopentyl methyl ether (CPME) and ethyl tert-butyl ether (ETBE), and the health score of the reprotoxic tetrahydrofurfuryl alcohol (THFA).

Solvents with high boiling points $\left(>200{ }^{\circ} \mathrm{C}\right)$ receive a red shaded environmental score of at least seven. This is for technological reasons (solvent removal, product drying), although on the assumption that solvent distillation is necessary, which may not always be the case. Although a perfectly valid concern it does mean that glycerol and other benign solvents appear to be environmentally damaging. In addition to a number of green alcohols and esters (including the bifunctional ethyl lactate), tert-amyl methyl ether (TAME) has been identified as an amenable replacement for less desirable ether solvents. Similarly, dimethyl carbonate scores well, but despite the categorisation in Fig. 15 acyclic carbonates are not sufficiently polar to be considered a direct substitute for classic dipolar aprotic solvents. Despite being considered as 'problematic', $p$-cymene has no red shaded scores, and as a renewable hydrocarbon is well placed to substitute toluene and other aromatic solvents [79-84]. Cyclic carbonates [70, 85], and Cyrene [69], suffer in the environmental assessment because of their high boiling points, but offer clear health advantages over classical dipolar aprotic solvents (Fig. 13). None of the suggested unconventional dipolar aprotic solvent have nitrogen or sulphur atoms that would result in $\mathrm{NO}_{\mathrm{x}}$ and $\mathrm{SO}_{\mathrm{x}}$ air pollution when incinerated. Furthermore cyclic carbonate and Cyrene have no known chronic toxicity issues.

The second solvent selection guide to extend its coverage to neoteric solvents is based on a computational similarity clustering of solvents [65]. Revealing their motivation, the authors state "existing solvent selection guides give only quasi-quantitative information about solvent greenness" [65]. In this new approach to designing a solvent selection guide, 151 solvents were assessed 


\begin{tabular}{|c|c|c|c|c|c|}
\hline Class & Solvent & $S$ & $\mathrm{H}$ & $\mathrm{E}$ & Conclusion* \\
\hline \multirow[t]{4}{*}{ Alcohols } & \multirow{4}{*}{$\begin{array}{l}\text { i-Butanol } \\
\text { i-Amyl alcohol } \\
\text { 1,3-Propanediol } \\
\text { Glycerol }\end{array}$} & 3 & 4 & 3 & \multirow{2}{*}{$\begin{array}{l}\text { Recommended } \\
\text { Recommended }\end{array}$} \\
\hline & & 3 & 2 & 3 & \\
\hline & & 1 & 1 & 7 & \multirow{2}{*}{$\begin{array}{l}\text { Problematic } \\
\text { Problematic }\end{array}$} \\
\hline & & 1 & 1 & 7 & \\
\hline \multirow[t]{5}{*}{ Esters } & $i$-Butyl acetate & 4 & 2 & 3 & \multirow{3}{*}{$\begin{array}{l}\text { Recommended } \\
\text { Recommended } \\
\text { Recommended }\end{array}$} \\
\hline & \multirow{4}{*}{$\begin{array}{l}\text { i-Amyl acetate } \\
\text { Glycol diacetate } \\
\text { v-Valerolactone } \\
\text { Diethyl succinate }\end{array}$} & 3 & 1 & 5 & \\
\hline & & 1 & 1 & 5 & \\
\hline & & 1 & 5 & 7 & Problematic \\
\hline & & 1 & 5 & 7 & Problematic \\
\hline \multirow[t]{3}{*}{ Ethers } & \multirow{3}{*}{$\begin{array}{l}\text { TAME } \\
\text { CPME } \\
\text { ETBE }\end{array}$} & 6 & 2 & 3 & Recommended \\
\hline & & 7 & 2 & 5 & \multirow{5}{*}{$\begin{array}{l}\text { Problematic } \\
\text { Problematic } \\
\text { Problematic } \\
\text { Problematic } \\
\text { Problematic }\end{array}$} \\
\hline & & 7 & 3 & 3 & \\
\hline \multirow[t]{3}{*}{ Hydrocarbons } & \multirow{3}{*}{$\begin{array}{l}d \text {-Limonene } \\
\text { Turpentine } \\
p \text {-Cymene }\end{array}$} & 4 & 2 & 7 & \\
\hline & & 4 & 2 & 7 & \\
\hline & & 4 & 5 & 5 & \\
\hline \multirow[t]{4}{*}{ Dipolar aprotic } & \multirow{4}{*}{$\begin{array}{l}\text { Dimethyl carbonate } \\
\text { Ethylene carbonate } \\
\text { Propylene carbonate } \\
\text { Cyrene }\end{array}$} & 4 & 1 & 3 & Recommended \\
\hline & & 1 & 2 & 7 & \multirow{5}{*}{$\begin{array}{l}\text { Problematic } \\
\text { Problematic } \\
\text { Problematic } \\
\text { Problematic } \\
\text { Problematic }\end{array}$} \\
\hline & & 1 & 2 & 7 & \\
\hline & & 1 & 2 & 7 & \\
\hline \multirow[t]{3}{*}{ Miscellaneous } & \multirow{3}{*}{$\begin{array}{l}\text { Ethyl lactate } \\
\text { Lactic acid } \\
\text { THFA }\end{array}$} & 3 & 4 & 5 & \\
\hline & & 1 & 4 & 7 & \\
\hline & & 1 & 9 & 5 & Hazardous \\
\hline \multicolumn{6}{|c|}{$\begin{array}{l}\text { *'Hazardous': one score of } 8 \text { or higher, or two scores between } 7 \text { and } 10 \text {. } \\
\text { 'Problematic': one score equal to } 7 \text {, or two scores between } 4 \text { and } 6 \text {. All other } \\
\text { solvents are recommended. }\end{array}$} \\
\hline
\end{tabular}

Fig. 15 Simplified version of the CHEM21 unconventional solvent selection guide

and grouped according to their physicochemical properties. These include melting point, boiling point, surface tension, etc. So that the greenness of the solvents can be ranked on a fair like-for-like basis, a cluster analysis grouped similar solvents together. Cluster 1 consists of non-polar and volatile solvents. Light aliphatic and olefinic hydrocarbons, aromatics, and chlorinated solvents are present in this cluster. Less volatile but still non-polar solvents form cluster 2 (including hydrophobic higher hydrocarbons, for example terpenes and long chain alcohols and esters). Cluster 3 is made up of polar, typically water soluble, solvents. The solvents in each cluster were then assessed according to 15 criteria (Table 6). If the data set is incomplete, the solvent is assessed according to lesser requirements (called confidence levels). The less data available on which to derive the greenness assessment, the less confident the user can be on the final ranking. Toxicology data especially is lacking for unconventional and novel bio-based solvents. The ranking is performed on a comparative basis within a cluster, and scores cannot be compared across clusters.

Generally cluster 1 contains the most toxic solvents. Given that the highest ranked solvent in this set is diethyl ether it is clear that greener alternatives to current non-polar and volatile solvents are needed, or better still a lessened dependence on VOC solvents more generally (diethyl ether is potentially peroxide forming with a very low flash point). Cluster 2 contains many solvents not 
Table 6 Criteria for a chemometric solvent selection guide

\begin{tabular}{|c|c|c|c|c|}
\hline \multicolumn{5}{|c|}{ Physicochemical clustering criteria } \\
\hline Melting point & \multicolumn{2}{|c|}{ Water solubility } & \multicolumn{2}{|r|}{ Vapour pressure } \\
\hline Boiling point & \multicolumn{2}{|c|}{$\log \left(K_{O W}\right)$} & \multicolumn{2}{|r|}{ Henry's law constant } \\
\hline Density & \multicolumn{2}{|c|}{$\log \left(K_{O A}\right)$} & \multicolumn{2}{|r|}{ Surface tension } \\
\hline \multirow[t]{2}{*}{ Greenness ranking criteria } & \multicolumn{4}{|c|}{ Assessment confidence level } \\
\hline & Highest & High & Medium & Low \\
\hline Feedstock renewability & Y & Y & Y & Y \\
\hline Recycling by distillation & Y & Y & Y & Y \\
\hline Combustion products & Y & Y & Y & Y \\
\hline Flammability & Y & Y & Y & Y \\
\hline $\log (B C F)$ & Y & Y & Y & Y \\
\hline Oral $L_{50}$ & Y & Y & Y & \\
\hline Inhalation $\mathrm{LC}_{50}$ & Y & Y & & \\
\hline IARC cancer class & Y & Y & & \\
\hline Other specific toxicology & Y & Y & & \\
\hline Fish $L_{50}$ & Y & Y & & \\
\hline Fish NOEL & Y & Y & & \\
\hline$B O D t_{1 / 2}$ & Y & Y & & \\
\hline Hydrolysis $t_{1 / 2}$ & Y & Y & & \\
\hline Flash point & Y & Y & & \\
\hline POCP & Y & & & \\
\hline
\end{tabular}

featured in other solvent selection guides, including fatty acid methyl esters (FAMEs) and terpenes, which fair reasonably well in the assessment. However it is the linear petrochemical hydrocarbons (dodecane, undecane, heptane) that are categorised as the greenest solvents in cluster 2 at the high confidence level. Cluster 3 solvents are less likely to be toxic to the aquatic environment and are more frequently bio-based than the other two clusters. Aside from a couple of chlorinated solvents, cluster 3 is mostly comprised of highly polar solvents (water, glycerol, ethanol, acetonitrile etc.).

How a lack of data influences the ranking of solvents can be demonstrated for selected solvents within cluster 2 (Fig. 16) [65]. Scores for the ranking are set between 1 and 0 , but only the relative position of the solvents is shown in Fig. 16, first being the greenest of the 35 solvents in cluster 2 . None of the solvents in cluster 2 have photochemical ozone creation potential (POCP) data, and so the highest confidence greenness assessment could not be performed. $n$-Heptane for example has all the data necessary to be ranked according to the high confidence level. Ranked third it is considered to be greener than methyl laurate (4th). Methyl oleate on the other hand can at best be ranked according to the medium confidence level. If comparing methyl oleate to other solvents, the same confidence level must be used, and only for cluster 2. A drastic fall in perceived greenness occurs for $n$-heptane when moving across to the medium and low confidence levels, where less data is applied in the ranking (Fig. 16). In general conventional alkanes and bio-based hydrocarbons make way for FAMEs at the medium and low confidence levels. Limonene and $p$-cymene are more resilient to a fall in ranking, in part because they are renewable and that is one of the five criteria remaining at the lowest confidence level. The contradictory interpretations of $n$-heptane, sometimes considered in the top three for greenness, but sometimes in the bottom 2 , strongly emphasises that data is paramount. More quality data is needed for less common solvents, but also what data is selected and used in a greenness assessment is crucial. The nature of green chemistry as an applied discipline is reliant on judgement to a degree. This means a consensus cannot be expected, and will always leave room for disagreement.

The chemometric approach to clustering and ranking solvents has reiterated that certain types of solvent have inherently undesirable characteristics. Therefore solvent selection on a direct 'like-for-like' substitution basis is restrictive. Relying only on the existing catalogue of largely conventional solvents, it is not possible to have a green solvent substitute readily available for every application. Green solvents tend to be similar (e.g., alcohols and esters) and so an abundance of green solvent options can be found in some areas of solvent use but a desperate 


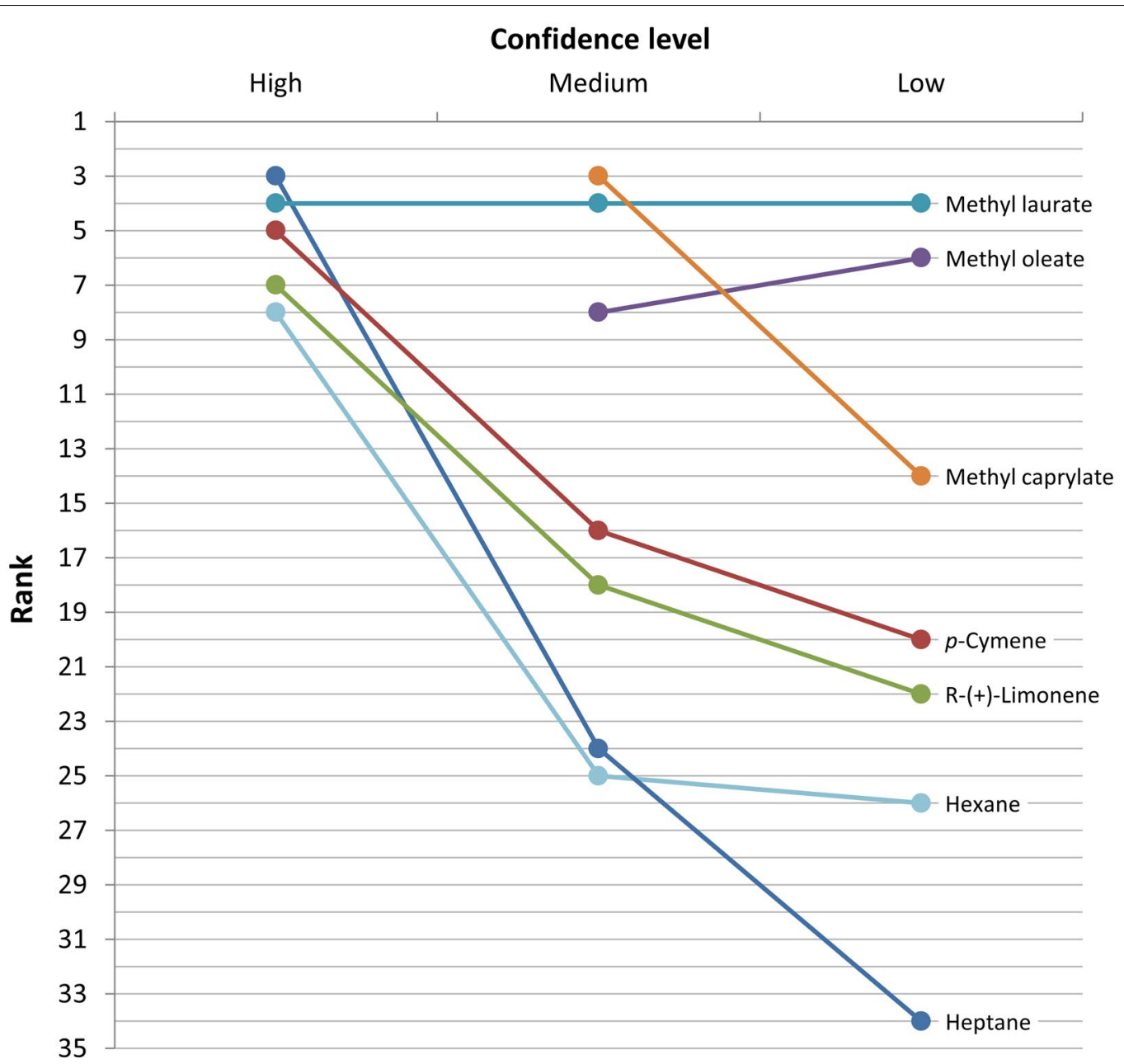

Fig. 16 Selected solvent rankings from cluster 2 of the chemometric solvent selection guide

need remains in others. What has also been shown is that the conclusions of a solvent selection guide can be completely reversed depending on what data is used, which certainly damages confidence in using these tools.

\section{Conclusions}

Past and present solvent selection guides for general use have been reviewed with the aim of clarifying the advantages and limitations of each. Attempts at solvent selection for EHS benefits (rather than just for regulatory compliance) by means of colour coded solvent selection guides demonstrates the growth in understanding surrounding solvent use in recent years. These user friendly tools communicate the issue clearly to users, creating awareness of greener alternatives and discourage the use of certain solvents in favour of others. Large reductions in undesirable solvent use have been reported as a result [48]. For all the positives brought by solvent selection guides, before now they have not been scrutinised closely enough in the reviews on this topic $[53,86]$. The necessity to subjectively choose categories and apply different weightings, and the level of interpretation required, means we must assess these tools with the same level of scientific interrogation that chemists would happily apply to more conventional research topics.

Upon completion of the survey of solvent selection guides conducted by Prat et al. [57], our understanding of solvent greenness as chemists, for the conventional solvents at least, would seem to have reassuringly converged (Table 4). The consensus between the solvent selection guides of the major pharmaceutical companies suggests a reasonable level of maturity in the field. Newer solvent selection guides for conventional solvents are essentially now repeating existing tools, reinforcing the consensus. The authors of this work suggest there is no need for more general purpose solvent selection guides of the familiar format because they are no longer providing any significant advancement in this field. The general agreement 
between solvent selection guides is not an indication that an ultimate and conclusive description of the concept of solvent greenness has been accomplished, but that the solvent selection guide format has reached its potential. The lack of sustainability criteria applied in solvent selection guides indicates that basically all solvent tools are indicative of a narrower set of requirements describing worker health and safety combined with environmental release issues. For instance, not even the renewability of the feedstock is considered in most solvent selection guides. There is an LCA category in the GSK solvent selection guide for process chemists (Fig. 10), but the input data for this assessment is not publicly available $[40,46]$.

One criticism of solvent selection guides is that the calculation behind the assessment is usually not transparent. Almost all solvent selection guides will combine values derived from unrelated physical properties, raising questions over the weighting of different EHS aspects, where and how to establish threshold values, and the actual meaning of the resulting scores. Openly available methodologies based on regulation thresholds have proven helpful in producing transparent assessments that can be applied to new solvents [32, 56]. Approaches to solvent selection where the methodology is changed to include more or less data have shown the assessment is very sensitive to what criteria are applied [65]. If the methodology is not clearly communicated it cannot be expected that potential users will trust the conclusions.

By whatever means a general purpose solvent selection guide is created, these tools are still unable to specifically guide solvent selection for particular applications. Reaction specific solvent selection guides are now available [87-89], which rank a set of solvents according to the observed performance (not greenness). The requirement of the solvent in chromatography as the mobile phase is so obvious in its importance that solvent guides for this application predate all other tools $[90,91]$, and has now been revived as a research topic [92, 93]. Technological requirements can be balanced against solvent greenness through general purpose solvent selection guides, and alternative methods of computational solvent optimisation $[65,94]$. This approach to separating technological and EHS considerations resolves a problem clearly evident in the CHEM21 solvent selection guide, where benign but high boiling solvents, including glycerol, are considered to have an undesirable environmental impact [56]. It is true that the recycling of low boiling, water immiscible solvents is lower in energy demand than other solvents [32]. However, a high boiling (and water miscible) solvent is greener in terms of its inherent solvent properties because worker exposure risks are less, and environmental impact, specifically aquatic toxicity and persistence, is generally lower too. What is clear is that alternatives to distillation, such as membrane separation need to be developed further [95]. New chemical systems such as tunable solvents can avoid distillation completely [6, 74], but for now are beyond the scope of solvent selection guides. The balance between opposing considerations is difficult to perfect, but to adequately communicate this to the user of the solvent selection guide is perhaps harder still. It is also true that the impact of a solvent depends on the industry in which it is used and how strict the controls on solvent emissions and waste are. This must also be considered by solvent users.

The future of solvent selection will inevitably require a greater sophistication in how solvents are chosen on the basis of a sustainable supply chain, and more work is needed in the area of application specific tools and life cycle assessments [96]. To do this more data will be required, especially for new solvents regarding their physical properties and their environmental impact. The role of the general purpose solvent selection guide is now only to expand its coverage to neoteric solvents so that they may be judged on a par with conventional solvents, and consequently stimulate research into the design of new solvents [97].

\section{Postscript}

After the original submission of this review, the GSK solvent selection guide [46], was updated featuring a new format [98]. More solvents have been added, and the categories for the numerical scoring system have been expanded. Whereas before the overall impacts were scored, such as 'waste' (Fig. 9), now the individual categories receive a score (incineration, biological treatment, etc.). In addition an overall colour coding of every solvent is provided. Regarding dipolar aprotic solvents, none are considered green, and only DMPU, DMSO, 1,3-dimethyl2-imidazolidinone, acetonitrile and propanenitrile have a yellow colour coding. Sulpholane and the remaining nitrogen containing dipolar aprotic solvents are shaded in red. Some of the new (bio-based) solvents introduced since the previous update are limonene (yellow), ethyl lactate (green), and cyrene (yellow). The supplementary information that accompanies the latest GSK solvent selection guide publication gives a detailed description of how the solvent scores were arrived at.

\section{Additional file}

Additional file 1. Complete details of the solvent selection guides and information on how scoring is conducted.

\section{Abbreviations}

ACS: American Chemical Society; BCF: bio-concentration factor; BOD: biological oxygen demand; CED: cumulative energy demand; CLP: classification, labelling and packaging; CPME: cyclopentyl methyl ether; DCE: 
1,2-dichloroethane; DCM: dichloromethane; DEGDME: diethylene glycol dimethyl ether; DMAc: N,N-dimethylacetamide; DME: dimethoxyethane; DMF: $\mathrm{N}, \mathrm{N}$-dimethylformamide; DMPU: dimethyl propylene urea; DMSO: dimethyl sulphoxide; EGDME: ethylene glycol dimethyl ether; EHS: environmental, health and safety; ETBE: ethyl $t$-butyl ether; FAME: fatty acid methyl ether; GCl: Green Chemistry Institute; GHS: Global Harmonized System; GSK: GlaxoSmithKline; IARC: International agency for research on cancer; ICH: International Conference on Harmonisation; IMI: innovative medicines initiative; $\mathrm{K}_{\mathrm{OA}}$ : octanol-air partition coefficient; $\mathrm{K}_{\mathrm{ow}}$ : octanol-water partition coefficient; $\mathrm{LC}_{50}$ : lethal concentration (50 \% test population); $L C A$ : life cycle assessment; $L D_{50}$ : lethal dose (50 \% test population); 2-MeTHF: 2-methyltetrahydrofuran; MEK: methyl ethyl ketone; MIBK: methyl isobutyl ketone; MJ: megajoules; NOEL: no observed effect limit; NMP: N-methylpyrrolidinone; PhCl: chlorobenzene; POCP: photochemical ozone creation potential; REACH: registration, evaluation, authorisation and restriction of chemicals; RAPEX: rapid alert system for dangerous non-food products; TAME: t-amyl methyl ether; TBME: tert-butyl methyl ether; THF: tetrahydrofuran; THFA: tetrahydrofurfuryl alcohol; SVHC: substances of very high concern; VOC: volatile organic compound.

\section{Authors' contributions}

FPB, SJ, GP and THMP reviewed the literature and produced the case studies detailing each solvent selection guide. JS analysed the outcome of each solvent selection guide and produced the comparisons found in this review, which were then revised with further input from GP and FPB. JHC, TJF, AJH and CRMC supervised the researchers preparing this manuscript and have reviewed and commented on this document during its development. JS organised the author contributions and lead the writing of the manuscript. All authors read and approved the final manuscript.

\section{Competing interests}

The authors of this manuscript have personally contributed to some of the solvent selection guides featured in this review. JS is a co-author of a previous version of the GSK solvent selection guide. CRMc is a co-author of the CHEM21 selection guide of classical- and less classical-solvents. GP is funded by the CHEM21 project which produced a number of the tools reviewed here. The manuscript is not foreseen to create any competitive or financial gain or loss to any person or institution, nor was it the intention to do so.

Received: 18 February 2016 Accepted: 13 May 2016

Published online: 23 May 2016

\section{References}

1. Pollet P, Davey EA, Ureña-Benavides EE, Eckert CA, Liotta CL (2014) Solvents for sustainable chemical processes. Green Chem 16:1034-1055

2. Breeden SW, Clark JH, Macquarrie DJ, Sherwood J (2012) Green Solvents. In: Zhang W, Cue BW Jr (eds) Green techniques for organic synthesis and medicinal chemistry. Wiley, Chichester, pp 241-261

3. Earle MJ, Seddon KR (2000) Ionic liquids green solvents for the future. Pure Appl Chem 72:1391-1398

4. Pena-Pereira F, Kloskowski A, Namieśnik J (2015) Perspectives on the replacement of harmful organic solvents in analytical methodologies: a framework toward the implementation of a novel generation of ecofriendly alternatives. Green Chem 17:3687-3705

5. Clark JH, Farmer TJ, Hunt AJ, Sherwood J (2015) Opportunities for biobased solvents created as petrochemical and fuel products transition towards renewable resources. Int J Mol Sci 16:17101-17159

6. Abou-Shehada S, Clark JH, Paggiola G, Sherwood J (2016) Tunable solvents: shades of green. Chem Eng Process 99:88-96

7. Constable DJC, Jimenez-Gonzalez C, Henderson RK (2007) Perspective on solvent use in the pharmaceutical industry. Org Process Res Dev 11:133-137

8. Ashcroft CP, Dunn PJ, Hayler JD, Wells AS (2015) Survey of solvent usage in papers published in Organic Process Research \& Development 1997-2012. Org Process Res Dev 19:740-747

9. Buhler DR, Reed DJ (1990) Ethel Browning's toxicity and metabolism of industrial solvents. In: Nitrogen and phosphorus solvents, vol 2, 2nd edn. Elsevier Science Publishers, Amsterdam
10. Sicaire AG, Vian M, Fine F, Joffre F, Carré $P$, Tostain $S$, Chemat F (2015) Alternative bio-based solvents for extraction of fat and oils: solubility prediction, global yield, extraction kinetics, chemical composition and cost of manufacturing. Int J Mol Sci 16:8430-8453

11. Virot M, Tomao V, Ginies C, Chemat F (2008) Total lipid extraction of food using $d$-limonene as an alternative to $n$-hexane. Chromatographia 68:311-313

12. Gissi A, Lombardo A, Roncaglioni A, Gadaleta D, Mangiatordi GF, Nicolotti O, Benfenati E (2015) Evaluation and comparison of benchmark QSAR models to predict a relevant REACH endpoint: the bioconcentration factor (BCF). Environ Res 137:398-409

13. Tebby C, Mombelli E, Pandard P, Péry ARR (2011) Exploring an ecotoxicity database with the OECD (Q)SAR Toolbox and DRAGON descriptors in order to prioritise testing on algae, daphnids, and fish. Sci Total Environ 409:3334-3343

14. International Labour Organization (1971) Benzene convention: convention concerning protection against hazards of poisoning arising from benzene. http://www.lo.org/dyn/normlex/en/f?p=NORMLEXPUB:12100: 0::NO::P12100_ILO_CODE:C136. Accessed 18 Dec 2015

15. World Health Organization (2015) IARC monographs on the evaluation of carcinogenic risks to humans. http://monographs.iarc.fr/ENG/Classification/index.php. Accessed 18 Dec 2015

16. United Nations Environment Programme (1987) The montreal protocol on substances that deplete the ozone layer. http://ozone.unep.org/en/ treaties-and-decisions/montreal-protocol-substances-deplete-ozonelayer. Accessed 18 Dec 2015

17. Liang Q, Newman PA, Daniel JS, Reimann S, Hall BD, Dutton G, Kuijpers LJM (2014) Constraining the carbon tetrachloride (CCl4) budget using its global trend and inter-hemispheric gradient. Geophys Res Lett 41:5307-5315

18. Finnish Safety and Chemicals Agency. (2013) Toluene substance evaluation report (under REACH). http://echa.europa.eu/documents/10162/ a58633d6-1620-4764-b3bf-6308cad42e8b. Accessed 18 Dec 2015

19. European Chemicals Agency (ECHA) (2015) Classification and labelling inventory. http://echa.europa.eu/information-on-chemicals/cl-inventorydatabase. Accessed 18 Dec 2015

20. Hossaini R, Chipperfield MP, Montzka SA, Rap A, Dhomse S, Feng W (2015) Efficiency of short-lived halogens at influencing climate through depletion of stratospheric ozone. Nat Geosci 8:186-190

21. Regulation (EC) No 1907/2006 of the European Parliament and of the Council of 18 December 2006 concerning the registration, evaluation, authorisation and restriction of chemicals (REACH), establishing a European chemicals agency, amending Directive 1999/45/EC and repealing Council Regulation (EEC) No 793/93 and Commission Regulation (EC) No 1488/94 as well as Council Directive 76/769/EEC and Commission Directives 91/155/EEC, 93/67/EEC, 93/105/EC and 2000/21/EC. EUR-Lex (2006) http://eur-lex.europa.eu/legal-content/EN/TXT/?uri=CELEX:020 06R1907-20140410. Accessed 4 Jan 2016

22. European Chemicals Agency (ECHA) (2015) Guidance on REACH. http:// echa.europa.eu/guidance-documents/guidance-on-reach. Accessed 4 Jan 2016

23. European Chemicals Agency (2015) List of restrictions. http://echa. europa.eu/addressing-chemicals-of-concern/restrictions/list-of-restrictions. Accessed 9 Sept 2015

24. European Commission (2015) Rapid Alert System for dangerous non-food products (RAPEX). http://ec.europa.eu/consumers/consumers_safety/ safety_products/rapex/index_en.htm. Accessed 18 Dec 2015

25. European Commission (2015) RAPEX notication reference A11/0116/14. Search for notification A11/0116/14. http://ec.europa.eu/consumers/ consumers_safety/safety_products/rapex/alerts. Accessed 3 May 2016

26. European Commission (2015) RAPEX notication reference A11/0079/15. Search for notification A11/0079/15. http://ec.europa.eu/consumers/ consumers_safety/safety_products/rapex/alerts. Accessed 3 May 2016

27. European Commission (2015) RAPEX notication reference A11/0072/15 Search for notification A11/0072/15. http://ec.europa.eu/consumers/ consumers_safety/safety_products/rapex/alerts. Accessed 3 May 2016

28. European Commission (2015) RAPEX notication reference A12/0840/15. Search for notification A12/0840/15. http://ec.europa.eu/consumers/ consumers_safety/safety_products/rapex/alerts. Accessed 3 May 2016

29. EUR-Lex (2008) Regulation (EC) No 1272/2008 of the European Parliament and of the Council of 16 December 2008 on classification, labelling 
and packaging of substances and mixtures, amending and repealing Directives 67/548/EEC and 1999/45/EC, and amending Regulation (EC) No 1907/2006. http://eur-lex.europa.eu/legal-content/en/ ALL/?uri=CELEX:32008R1272. Accessed 4 Jan 2016

30. European Chemicals Agency (ECHA) (2015) Candidate list of substances of very high concern for authorisation. http://echa.europa.eu/candidatelist-table. Accessed 4 Jan 2016

31. Kerton FM, Marriott R (2013) Alternative solvents for green chemistry, 2nd edn. RSC publishing, Cambridge

32. Capello C, Fischer U, Hungerbühler K (2007) What is a green solvent? A comprehensive framework for the environmental assessment of solvents. Green Chem 9:927-934

33. Capello C, Wernet G, Sutter J, Hellweg S, Hungerbühler K (2009) A comprehensive environmental assessment of petrochemical solvent production. Int J Life Cycle Assess 14:467-479

34. ETH Zurich (2008) EHS assessment tool. http://www.sust-chem.ethz.ch/ tools/ehs. Accessed 18 Dec 2015

35. Rani MAA, Borduas N, Colquhoun V, Hanley R, Johnson H, Larger S, Lickiss PD, Llopis-Mestre V, Luu S, Mogstad M, Oczipka P, Sherwood JR, Welton T, Xing JY (2014) The potential of methylsiloxanes as solvents for synthetic chemistry applications. Green Chem 16:1282-1296

36. Le Cloirec P (2012) Treatments of polluted emissions from incinerator gases: a succinct review. Rev Environ Sci Bio/Technol 11:381-392

37. Curzons AD, Constable DC, Cunningham VL (1999) Solvent selection guide: a guide to the integration of environmental, health and safety criteria into the selection of solvents. Clean Prod Process 1:82-90

38. Slater CS, Savelski M (2007) A method to characterize the greenness of solvents used in pharmaceutical manufacture. J Environ Sci Health Part A Toxic/Hazard Subst Environ Eng 42:1595-1605

39. Rowan University (2007) Solvent selection table, login required (username "guest", password "guest"). http://www.rowan.edu/greenengineering. Accessed 18 Dec 2015

40. Jiménez-González C, Curzons AD, Constable DJC, Cunningham VL (2004) Expanding GSK's solvent selection guide-application of life cycle assessment to enhance solvent selections. Clean Technol Environ Policy 7:42-50

41. Dunn PJ, Galvin S (2004) Kevin Hettenbach K. The development of an environmentally benign synthesis of sildenafil citrate $\left(\right.$ Viagra $\left.^{\mathrm{TM}}\right)$ and its assessment by green chemistry metrics. Green Chem 6:43-48

42. Tanaka K, Toda F (2000) Solvent-free organic synthesis. Chem Rev 100:1025-1074

43. James SL, Adams CJ, Bolm C, Braga D, Collier P, Friščić T, Grepioni F, Harris KDM, Hyett G, Jones W, Krebs A, Mack J, Maini L, Orpen AG, Parkin IP, Shearouse WC, Steed JW, Waddell DC (2012) Mechanochemistry: opportunities for new and cleaner synthesis. Chem Soc Rev 41:413-447

44. Reichardt C, Welton $T$ (2011) Solvents and solvent effects in organic chemistry, 4th edn. Wiley-VCH, Weinheim

45. Matlack AS (2001) Introduction to green chemistry. Marcel Dekker, New York, p 201

46. Henderson RK, Jiménez-González C, Constable DJC, Alston SR, Inglis GGA, Fisher G, Sherwood J, Binks SP, Curzons AD (2011) Expanding GSK's solvent selection guide - embedding sustainability into solvent selection starting at medicinal chemistry. Green Chem 13:854-862

47. Prat D, Pardigon O, Flemming HW, Letestu S, Ducandas V, Isnard P, Guntrum E, Senac T, Ruisseau S, Cruciani P, Hosek P (2013) Sanofi's solvent selection guide: a step toward more sustainable processes. Org Process Res Dev 17:1517-1525

48. Kim Alfonsi K, Colberg J, Dunn PJ, Fevig T, Jennings S, Johnson TA, Kleine HP, Knight C, Nagy MA, Perry DA, Stefaniak M (2008) Green chemistry tools to influence a medicinal chemistry and research chemistry based organisation. Green Chem 10:31-36

49. Ekins S, Clark AM, Williams AJ (2013) Incorporating green chemistry concepts into mobile chemistry applications and their potential uses. ACS Sustain Chem Eng 1:8-13

50. Royal Society of Chemistry (2011) GSK solvent selection guide 2009 (supplementary information relating to reference 43). http://www.rsc.org/ suppdata/gc/c0/c0gc00918k/c0gc00918k.pdf. Accessed 18 Dec 2015

51. Zhao R, Cabezas H, Nishtala SR (2000) The design of technologically effective and environmentally benign solvent substitutes. In: Anastas PT, Heine LG, Williamson TC (eds) Green chemical syntheses and processes. American Chemcial Society, Washington DC, pp 230-243
52. US Food and Drug Administration (FDA) (2012) Guidance for industry: Q3C tables and list (revision 2). http://www.fda.gov/downloads/Drugs/ GuidanceComplianceRegulatoryInformation/Guidances/ucm073395.pdf. Accessed 4 Jan 2016

53. Eastman HE, Jamieson C, Watson AJB (2015) Development of solvent selection guides. Aldrichimica Acta 48:51-55

54. American Chemical Society (ACS) (2015) The ACS GCl pharmaceutical roundtable solvent selection guide. http://www.acs.org/content/acs/ en/greenchemistry/research-innovation/research-topics/solvents.html. Accessed 4 Jan 2016

55. Hargreaves CR, Manley JB (2015) Collaboration to deliver a solvent selection guide for the pharmaceutical industry. ACS GCI pharmaceutical roundtable. http://www.acs.org/content/dam/acsorg/greenchemistry/industriainnovation/roundtable/solvent-selection-guide.pdf. Accessed 4 Jan 2016

56. Prat D, Wells A, Hayler J, Sneddon H, McElroy CR, Abou-Shehada S, Dunn PJ (2016) CHEM21 selection guide of classical- and less classical-solvents. Green Chem 18:288-296

57. Prat D, Hayler J, Wells A (2014) A survey of solvent selection guides. Green Chem 16:4546-4551

58. Tilstam U (2012) Sulfolane: a versatile dipolar aprotic solvent. Org Process Res Dev 16:1273-1278

59. Phillips Chemical Company (2015) Safety datasheet for sulpholane, Chevron. http://www.cpchem.com/bl/specchem/en-us/Pages/SulfolaneW. aspx. Accessed 9 May 2016

60. Lo CC, Chao PM (1990) Replacement of carcinogenic solvent HMPA by DMI in insect sex pheromone synthesis. J Chem Ecol 16:3245-3253

61. Mukhopadhyay T, Seebach D (1982) Substitution of HMPT by the cyclic urea DMPU as a cosolvent for highly reactive nucleophiles and bases. Helv Chim Acta 65:385-391

62. Li Z, Smith KH, Stevens GW (2015) The use of environmentally sustainable bio-derived solvents in solvent extraction applications-a review. Chin J Chem Eng 24:215-220

63. Gu Y, Jérôme F (2013) Bio-based solvents: an emerging generation of fluids for the design of eco-efficient processes in catalysis and organic chemistry. Chem Soc Rev 42:9550-9570

64. Corrêa AG, Paixão MW, Schwab RS (2015) Application of bio-based solvents in catalysis. Curr Org Synth 12:675-695

65. Tobiszewski M, Tsakovski S, Simeonov V, Namieśnik J, Pena-Pereira F (2015) A solvent selection guide based on chemometrics and multicriteria decision analysis. Green Chem 17:4773-4785

66. Moity L, Durand M, Benazzouz A, Pierlot C, Molinier V, Aubry JM (2012) Panorama of sustainable solvents using the COSMO-RS approach. Green Chem 14:1132-1145

67. European Commission GROWTH Programme (DG Research) (2006) Medium and long-term opportunities and risk of the biotechnological production of bulk chemicals from renewable resources-the potential of white biotechnology. http://www.bio-economy.net/applications/files/ Brew_project_report.pdf. Accessed 18 Dec 2015

68. Pace V, Hoyos P, Castoldi L, Domínguez de María P, Alcántara AR (2012) 2-Methyltetrahydrofuran (2-MeTHF) a biomass-derived solvent with broad application in organic chemistry. ChemSusChem 5:1369-1379

69. Sherwood J, de Bruyn M, Constantinou A, Moity L, McElroy CR, Farmer TJ, Duncan T, Raverty W, Hunt AJ, Clark JH (2014) Dihydrolevoglucosenone (cyrene) as a bio-based alternative for dipolar aprotic solvents. Chem Commun 50:9650-9652

70. Parker HL, Sherwood J, Hunt AJ, Clark JH (2014) Cyclic carbonates as green alternative solvents for the Heck reaction. ACS Sustain Chem Eng 2:1739-1742

71. Hallett JP, Welton T (2011) Room-temperature ionic liquids: solvents for synthesis and catalysis 2. Chem Rev 111:3508-3576

72. Zhou B, Yang J, Li M, Gu Y (2011) Gluconic acid aqueous solution as a sustainable and recyclable promoting medium for organic reactions. Green Chem 13:2204-2211

73. Arai K, Smith RL Jr, Aida TM (2009) Decentralized chemical processes with supercritical fluid technology for sustainable society. J Supercrit Fluids 47:628-636

74. Jessop PG (2011) Searching for green solvents. Green Chem 13:1391-1398

75. Farmer TJ, Mascal M (2015) Platform molecules. In: Clark JH, Deswarte F (eds) Introduction to chemicals from biomass, 2nd edn. Wiley, Chichester, pp 89-156 
76. Kelkar S, Saffron CM, Andreassi K, Li Z, Murkute A, Miller DJ, Pinnavaia TJ, Kriegele RM (2015) A survey of catalysts for aromatics from fast pyrolysis of biomass. Appl Catal B 174-175:85-95

77. Min K, Kim S, Yum T, Kim Y, Sang BI, Um Y (2013) Conversion of levulinic acid to 2-butanone by acetoacetate decarboxylase from Clostridium acetobutylicum. Appl Microbiol Biotechnol 97:5627-5634

78. Corker EC, Mentzel UV, Mielby J, Riisager A, Fehrmann R (2013) An alternative pathway for production of acetonitrile: ruthenium catalysed aerobic dehydrogenation of ethylamine. Green Chem 15:928-933

79. Clark JH, Macquarrie DJ, Sherwood J (2012) A quantitative comparison between conventional and bio-derived solvents from citrus waste in esterification and amidation kinetic studies. Green Chem 14:90-93

80. Clark JH, Fitzpatrick EM, Macquarrie DJ, Pfaltzgraff LA, Sherwood J (2012) p-Cymenesulphonic acid: an organic acid synthesised from citrus waste. Catal Today 190:144-149

81. Clark JH, Macquarrie DJ, Sherwood J (2013) The combined role of catalysis and solvent effects on the Biginelli reaction: improving efficiency and sustainability. Chem Eur J 19:5174-5182

82. Paggiola G, Hunt AJ, McElroy CR, Sherwood J, Clark JH (2014) Biocatalysis in bio-derived solvents: an improved approach for medium optimisation. Green Chem 16:2107-2110

83. Hughes BC, Lu Z, Jenkins DM (2014) The final unadorned tris(azolyl) borate: finishing what Trofimenko started in 1966. Chem Commun 50:5273-5275

84. Xia AB, Wu C, Wang T, Zhang YP, Du XH, Zhong AG, Xu DQ, Xu ZY (2014) Enantioselective cascade oxa-michael-michael reactions of 2-hydroxynitrostyrenes with enones using a prolinol thioether catalyst. Adv Synth Catal 356:1753-1760

85. North M, Villuendas P (2010) A chiral solvent effect in asymmetric organocatalysis. Org Lett 12:2378-2381

86. Welton T (2015) Solvents and sustainable chemistry. Proc R Soc A 471:20150502

87. Skowerski K, Białecki J, Tracz A, Olszewski TK (2014) An attempt to provide an environmentally friendly solvent selection guide for olefin metathesis. Green Chem 16:1125-1130
88. McGonagle Fl, MacMillan DS, Murray J, Sneddon HF, Jamieson C, Watson AJB (2013) Development of a solvent selection guide for aldehyde-based direct reductive amination processes. Green Chem 15:1159-1165

89. MacMillan DS, Murray J, Sneddon HF, Jamieson C, Watson AJB (2013) Evaluation of alternative solvents in common amide coupling reactions: replacement of dichloromethane and N,N-dimethylformamide. Green Chem 15:596-600

90. Thoma JA (1965) Selection of a chromatographic solvent. Anal Chem 37:500-508

91. Abbott TP, Kleiman R (1991) Solvent selection guide for counter-current chromatography. J Chromatogr A 538:109-118

92. Taygerly JP, Miller LM, Yee A, Peterson EA (2012) A convenient guide to help select replacement solvents for dichloromethane in chromatography. Green Chem 14:3020-3025

93. MacMillan DS, Murray J, Sneddon HF, Jamieson C, Watson AJB (2012) Replacement of dichloromethane within chromatographic purification: a guide to alternative solvents. Green Chem 14:3016-3019

94. Murray PM, Bellany F, Benhamou L, Bučar DK, Tabor AB, Sheppard TD (2016) The application of design of experiments (DoE) reaction optimisation and solvent selection in the development of new synthetic chemistry. Org Biomol Chem 14:2373-2384

95. Vankelecom IFJ, Gevers LEM (2005) Membrane Processes. In: Afonso CAM Crespo JG (eds) Green separation processes fundamentals and applications. Wiley-VCH, Weinheim, pp 251-270

96. Diorazio LJ, Hose DRJ, Adlington NK (2016) Toward a more holistic framework for solvent selection. Org Process Res Dev 20:760-773

97. Vanderveen JR, Durelle J, Jessop PG (2014) Design and evaluation of switchable-hydrophilicity solvents. Green Chem 16:1187-1197

98. Alder CM, Hayler JD, Henderson RK, Redman AM, Shukla L, Shuster LE, Sneddon HF (2016) Updating and further expanding GSK's solvent sustainability guide. Green Chem. doi:10.1039/C6GC00611F

\section{Submit your manuscript to a SpringerOpen ${ }^{\odot}$ journal and benefit from:}

- Convenient online submission

- Rigorous peer review

- Immediate publication on acceptance

- Open access: articles freely available online

- High visibility within the field

- Retaining the copyright to your article

Submit your next manuscript at springeropen.com 